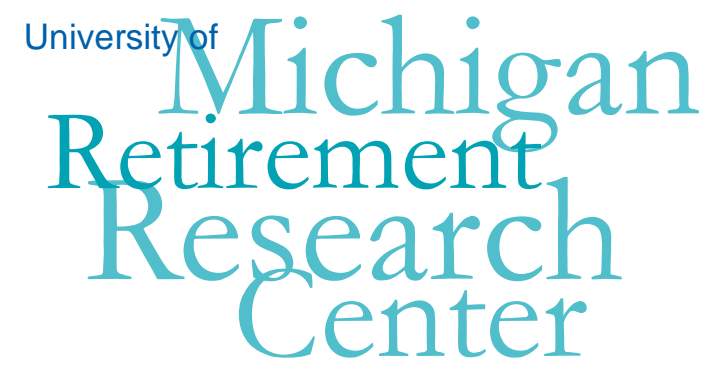

Working Paper

WP 2009-220

How Common is "Parking" Among Social Security Disability Insurance (SSDI)

Beneficiaries? Evidence from the 1999 Change in the Level of Substantial Gainful Activity (SGA)

Jody Schimmel, David C. Stapleton and Jae Song

\begin{tabular}{|l|l|l|}
\hline $\mathrm{M}$ & $\mathrm{R}$ \\
\hline $\mathrm{R}$ & $\mathrm{C}$ \\
\hline
\end{tabular}$\quad$ Project \#: UM09-02 



\title{
How Common is "Parking" Among Social Security Disability Insurance (SSDI) Beneficiaries? Evidence from the 1999 Change in the Level of Substantial Gainful Activity (SGA)
}

\author{
Jody Schimmel \\ Mathematica \\ David C. Stapleton \\ Mathematica \\ Jae Song \\ Social Security Administration
}

October 2010

\author{
Michigan Retirement Research Center \\ University of Michigan \\ P.O. Box 1248 \\ Ann Arbor, MI 48104 \\ http://www.mrrc.isr.umich.edu/ \\ (734) 615-0422
}

\section{Acknowledgements}

This work was supported by a grant from the Social Security Administration through the Michigan Retirement Research Center (Grant \# 10-M-98362-5-01). The findings and conclusions expressed are solely those of the author and do not represent the views of the Social Security Administration, any agency of the Federal government, or the Michigan Retirement Research Center.

\section{Regents of the University of Michigan}

Julia Donovan Darrow, Ann Arbor; Laurence B. Deitch, Bingham Farms; Denise Ilitch, Bingham Farms; Olivia P. Maynard, Goodrich; Andrea Fischer Newman, Ann Arbor; Andrew C. Richner, Grosse Pointe Park; S. Martin Taylor, Gross Pointe Farms; Katherine E. White, Ann Arbor; Mary Sue Coleman, ex officio 


\title{
How Common is "Parking" Among Social Security Disability Insurance (SSDI) Beneficiaries? Evidence from the 1999 Change in the Level of Substantial Gainful Activity (SGA)
}

\begin{abstract}
Fewer Social Security Disability Insurance (DI) beneficiaries have their earnings suspended or terminated because of work than those who are actually working, partly because beneficiaries "park" earnings at a level below substantial gainful activity (SGA) to retain benefits. We assess the extent of parking by examining how beneficiary earnings and months off the rolls for work responded to a 1999 change in the SGA level for non-blind beneficiaries from $\$ 500$ to $\$ 700$ per month. Specifically, our difference-in-difference analysis compares longitudinal data for two beneficiary cohorts with different incentives to park their earnings; one experienced the increased SGA level the first year after its Trial Work Period (TWP), when beneficiaries can earn any amount without losing benefits, while the two-year-earlier cohort did not. The impact of the increased SGA level is consistent with parking, but its magnitude small. The reduction in TWP completers with earnings less than \$500 was 1.0 percentage points, the reduction in the percentage with earnings over $\$ 700$ was 1.2 percentage points, and the increase for those with earnings between $\$ 500$ and $\$ 700$ was 2.2 percentage points. However, there was no change in mean earnings; small increases for those with relatively low earnings were offset by reductions for those with relatively high earnings. The SGA increase had a significant negative effect on the average number of months that beneficiaries were off the rolls for work; the effect was largestabout six-tenths of a month-for those who earned \$500 to \$700 during in year they completed their TWP.
\end{abstract}




\section{INTRODUCTION}

The Social Security Disability Insurance (DI) program is designed to support qualified individuals who are unable to engage in "substantial gainful activity" (SGA) due to a medically determinable physical or mental impairment that is expected to result in death or last for at least a year. ${ }^{1}$ Growth in the DI rolls in recent decades has been substantial; from 2000 to 2007 alone, the number of disabled worker beneficiaries increased by approximately two million, to more than seven million beneficiaries (SSA 2008). Autor and Duggan (2006) document some of the reasons for this rapid expansion: aging of the labor force, growth in the percentage of women that meet the program's work history requirements, changes in eligibility criteria, rise in the value of the Medicare benefits for which DI beneficiaries attain eligibility after 24 months on the rolls, and a rise in the after-tax DI replacement rate for low-wage workers.

In addition to the rising number of people who receive DI benefits, employment rates among beneficiaries have been declining over the years. Employment among working-age people with disabilities is significantly lower than for those without disabilities - in 2008, 39 percent of those with disabilities worked, compared with 77 percent of those without disabilities (United States Census Bureau 2009). This differential has not improved in recent decades, and in fact, seems to have worsened (Weathers and Wittenburg 2009).

Once workers enter the DI program, a substantial minority returns to work, but a much smaller share leaves the rolls because of work. In each year, the number who leaves the rolls is minimal, but over time, more beneficiaries do ultimately have their benefits terminated because they are working. For instance, of those who received their DI awards in 1996, 28 percent had annual earnings of at

\footnotetext{
1 Individuals who qualify based on their own earnings record must have worked in a Social Security-covered position for 5 of the last 10 years.
} 
least $\$ 1,000$ in the next 10 years, but only 6.5 percent had their benefits suspended for at least a month because of work, and only 3.7 percent had their benefits terminated because of work (Stapleton et al. 2010a).

One reason that the percentage of beneficiaries who have their earnings suspended or terminated because of work is far lower than the percentage that return to work is because of "parking"-beneficiaries keeping their earnings below the level considered to be SGA in order to retain benefits. In 2010 , this amount is $\$ 1,000$ monthly for non-blind beneficiaries, and $\$ 1,640$ for blind beneficiaries (SSA 2010). If beneficiaries engage in SGA for a sustained period of time, they risk losing their DI benefits (described in more detail below). The complete loss of benefits as earnings increase from just below SGA earnings to just above is often called the "cash cliff." Unless the earnings increase is large enough to more than make up for the benefit loss at that point, total income from earnings plus benefits actually declines. Hence, there is strong incentive to "park" — to keep earnings just below the SGA level. Anecdotes about this behavior are widespread, but no statistics on the extent of this phenomenon are available.

If parking is widespread, then policy reforms designed to increase work incentives for SSDI beneficiaries capable of SGA could potentially increase beneficiary earnings and reduce reliance on benefits. A $\$ 1$-for $\$ 2$ benefit offset for earnings above the SGA level, currently being tested by the Social Security Administration (SSA), is an important example of such a reform. Widespread parking might also explain why so few beneficiaries have exited the rolls under the Ticket to Work program (Stapleton et al. 2008). It would also suggest that increases in the SGA level might induce increases in SSDI entry by those able to engage in SGA. If, instead, parking is fairly rare, then efforts to address the work incentive issue only are not likely to have large impacts on earnings and benefits, parking is not an important reason for low exit rates under Ticket, and SSDI entry is likely not very sensitive to modest increases in the SGA level. 
In this paper we investigate on how common parking is among DI beneficiaries by examining how a major change in the non-blind SGA level affected beneficiary earnings and months off the rolls for work. In July 1999, the SGA level for non-blind beneficiaries increased from $\$ 500$ per month to $\$ 700$ (SSA 2010). Prior to this time, the non-blind SGA level had been nominally set at $\$ 500$ since 1990. After the 1999 increase, the non-blind SGA level was indexed to the average wage index (AWI), and, as a result, has increased nominally in every subsequent year except 2010. While the SGA level for non-blind beneficiaries increased substantially in 1999, the SGA level for statutorily blind individuals increased only because of the small AWI adjustment (Table I.1).

Previous studies have not found a significant impact of the change in the SGA level on individual employment and earnings, but there are three reasons why they might not have detected such behavior, even if it were substantial. First, earlier studies have not distinguished between blind and non-blind beneficiaries. Second, and perhaps more importantly, they have not distinguished between those who have completed the Trial Work Period (TWP) and those who have not. The TWP consists of nine months (not necessarily consecutive) over a rolling 60 -month period during which the beneficiary can earn any amount without loss of benefits. We address these two limitations by using longitudinal SSA administrative data on annual cohorts of non-blind TWP completers, focusing on the period just after they complete the TWP.

The third limitation of previous studies is that they did not allow for the disparate effects of an increase in the SGA earnings level on those earning below the old SGA level and on those who earned so much under the old SGA that they had left the rolls for work. In theory, an increase in the SGA level could induce some in this high-earnings group to reduce their earnings, countering any positive impact of the SGA increase on the earnings of those with lower earnings. These offsetting effects might account for the absence of a substantial impact on the average earnings of beneficiaries 
in earlier studies. We address this limitation by studying changes in earnings for individuals grouped by the level of their earnings during the year in which they completed the TWP.

Table I.1. Substantial Gainful Activity (SGA) Level for Blind and Non-Blind DI Beneficiaries, 19952006

\begin{tabular}{lcc}
\hline Year & Non-Blind SCA $(\$)$ & Blind SCA $(\$)$ \\
\hline 1995 & 500 & 940 \\
1996 & 500 & 960 \\
1997 & 500 & 1,000 \\
1998 & 500 & 1,050 \\
1999 & $500 / 700^{\mathrm{a}}$ & 1,110 \\
2000 & 700 & 1,170 \\
2001 & 740 & 1,240 \\
2002 & 780 & 1,300 \\
2003 & 800 & 1,330 \\
2004 & 810 & 1,350 \\
2005 & 830 & 1,380 \\
2006 & 860 & 1,450 \\
\hline
\end{tabular}

Source: SSA (2010).

${ }^{a}$ Nominal non-blind SGA level increased from $\$ 500$ to $\$ 700$ on July 1,1999 .

We exploit the change in the non-blind SGA level in 1999 to assess the extent to which individuals engage in parking behavior. Our analysis compares the longitudinal earnings and time off the rolls for work of the 1998 TWP cohort to corresponding outcomes for the 1996 TWP cohort. These two cohorts faced the same nominal SGA level in the year they completed the TWP, but the nominal value for the 1998 cohort increased by $\$ 200$ halfway through the first year after TWP completion, whereas it remained the same for the 1996 cohort until halfway through the third year after TWP completion. Our difference-in-difference (DD) methodology compares changes from the TWP completion year to two years after TWP completion for the 1998 cohort (spanning the increase in the SGA level) to corresponding changes for the 1996 cohort. The effects of the increase in the SGA level are clearly evident in the data, but their size is not very large.

In the next section, we describe the "work incentive" features of the DI program, which were designed to provide beneficiaries with an opportunity to test their ability to engage in SGA without immediate loss of benefits, and consider the theoretical impacts of an increase in the SGA level on 
earnings and benefit receipt. In Section III, we review the earlier literature on the effect of changes in the SGA level on beneficiary earnings. Section IV describes our data and sample, and Section V describes the DD methodology we use to identify the impact of the increase in the SGA level. Section VI presents earnings distributions of successive TWP cohorts, Section VII presents the results of our DD estimates, and Section VIII summarizes findings from alternative specifications and robustness checks. Section IX concludes by providing estimates about the extent to which beneficiaries overall engage in parking and a discussion of policy implications. 
This page has been left blank for double-sided copying. 


\section{BACKGROUND AND CONCEPTUAL DISCUSSION}

The SGA earnings level is closely tied to the statutory definition of disability for adults, as described in the introduction. SSA considers a person to be engaged in SGA, and therefore not disabled by the statutory definition, if unsubsidized earnings, net of any impairment-related work expenses, exceed the SGA level. Hence, beneficiaries may work, as long as the work is not considered to be SGA. The TWP was designed to encourage beneficiaries to return to SGA, by giving them a chance to test their ability to do so without benefit loss. An individual's TWP lasts for nine (not necessarily consecutive) months in a rolling 60-month period, meaning that over the course of any five-year period, a beneficiary can earn any amount for up to nine months and still remain on the SSDI rolls.

Months with sufficiently low earnings do not count toward the nine-month TWP limit. The TWP earnings limit from 1990 to 2000 was $\$ 200$ per month (or 40 hours of self-employment); it was increased to $\$ 530$ monthly (or 80 hours of self-employment) in 2001 and has been indexed to the AWI in each year since. In 2009, the monthly TWP limit was $\$ 700$. In other words, only months in which a beneficiary earned more than $\$ 700$ in 2009 counted toward his or her TWP. The TWP limit is the same for both blind and non-blind SSDI beneficiaries. Because of the change in the TWP limit in 2001, we restrict our analysis to cohorts of TWP completers prior to that year, since the earnings distributions of cohorts that completed the TWP before and after that change could be substantially different.

After exhausting the TWP, the beneficiary enters the Extended Period of Eligibility (EPE), and benefits continue indefinitely if the beneficiary does not engage in SGA. If he or she does have earnings above the SGA level, benefits are paid for three additional Grace Period (GP) months. After that point, benefits are suspended in full during each month that the beneficiary engages in SGA, but otherwise are paid in full until the $36^{\text {th }}$ EPE month. If earnings are above SGA in the $36^{\text {th }}$ 
month, benefits are terminated; otherwise full benefits continue until the first month of SGA after GP completion, at which point they are terminated. This structure of benefits explains why at least some fraction of beneficiaries may engage in parking behavior. During the TWP and GP, beneficiaries have little incentive to restrain earnings, as benefits continue regardless of the amount of earnings in those months. After finishing the TWP and GP, however, there is strong incentive to restrain earnings below the SGA level.

Among beneficiaries who have completed their TWP and are in their EPE, the expected effect of an SGA increase on earnings and months off the rolls depends on what their earnings would have been in the absence of the increase. First, those who would have had earnings below the initial SGA level might increase their earnings by up to $\$ 200$, because they could do so without exceeding the new, higher SGA level. For example, someone who kept his or her monthly earnings at $\$ 475$ to stay below an SGA level of $\$ 500$ might now earn $\$ 675$ if the SGA level were increased to $\$ 700$. For these types of individuals, we would expect to see higher average annual earnings but no change in the number of months spent off the rolls for work, since these beneficiaries would continue to receive benefits in each month they worked.

Second, those who would have earned above the new SGA and thus lost their benefits, might make an effort to earn less than the new SGA level so as to retain benefits. Consider, for example, someone with an SSDI benefit of $\$ 600$ who has the potential to earn $\$ 1,200$. With an SGA level of $\$ 500$, the beneficiary could retain benefits by keeping earnings just below $\$ 500$, for total income of just under $\$ 1,100$, or could forego benefits and increase income to $\$ 1,200$. Under an SGA level of $\$ 700$, this same individual could retain benefits by keeping earnings just below $\$ 700$, for total income of just under $\$ 1,300$ - more than the beneficiary would earn if he or she were to forego benefits. This individual has a stronger incentive to keep earnings below the new SGA level than below the initial SGA level, and is therefore more likely to reduce earnings and retain benefits under 
the new SGA level. More generally, we would expect the earnings of those who would have earned above $\$ 700$ under the old SGA level to decrease under the new SGA level, and for them to spend fewer months off the rolls for work.

Third, those who would have earned an amount between the initial \$500 SGA level and the new $\$ 700$ level, and thus left the rolls, are not likely to change the amount they earn by much but will be able to retain their benefits. These individuals would have left the rolls under the initial SGA level despite the strong incentive to restrain their earnings and remain on the rolls.

Given the relationship between earnings in the absence of the SGA increase and the effect of the SGA increase on earnings, we would expect to see a change in the cumulative distribution of earnings for TWP completers much like the stylized change displayed in Figure II.1, assuming that all else is held constant. The percentage of those with earnings below the initial SGA is expected to fall, the percentage with earnings above the new SGA is also expected to fall, and the old and new cumulative distributions will cross at some level of earnings between the old and new SGA.

Figure II.1 Stylized Shift in the Earnings Distribution of TWP Completers After an SGA Increase

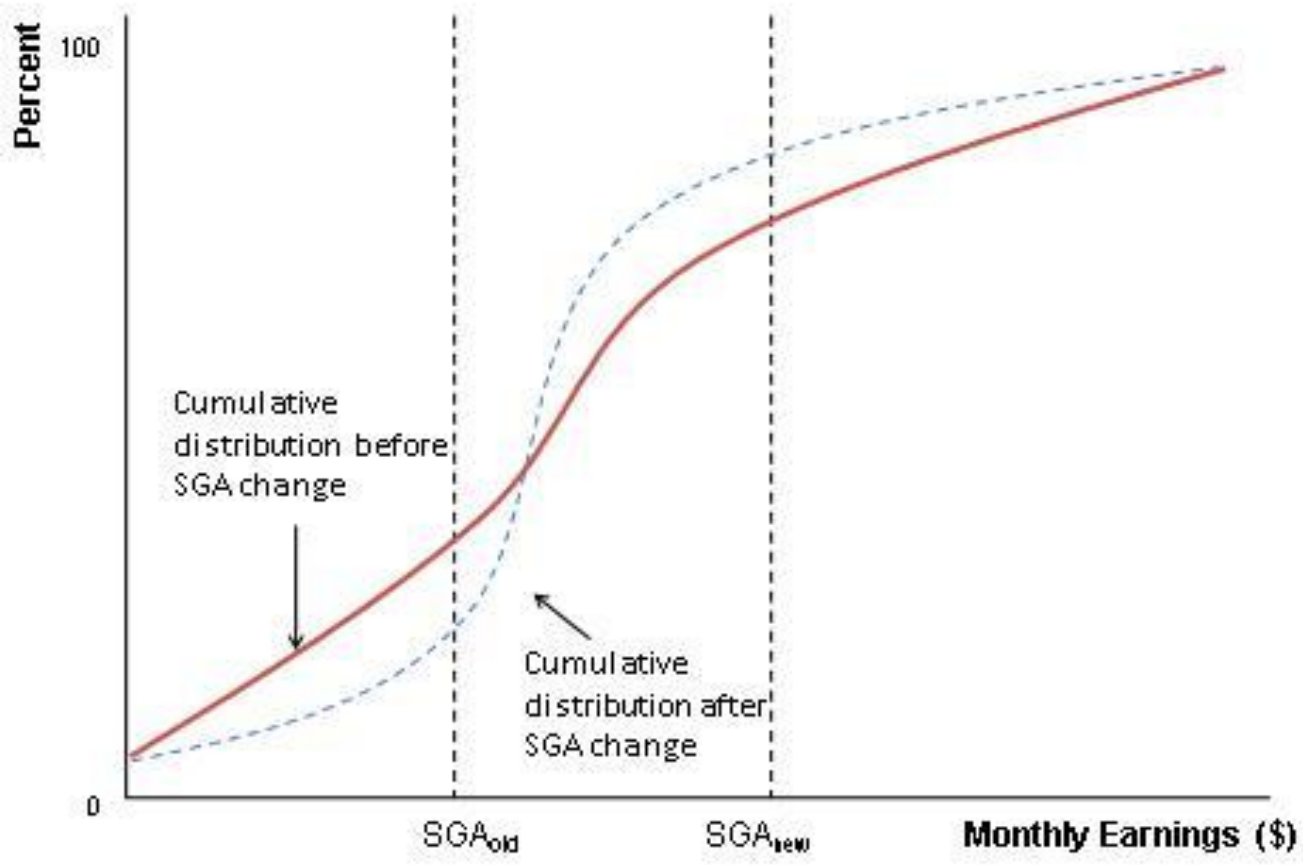


This page has been left blank for double-sided copying. 


\section{LITERATURE REVIEW}

To our knowledge, there have been no rigorous studies of parking behavior, and relatively few studies that assess the impact of SGA changes. Previous work that has studied the impact of increases in the SGA level has found little overall impact on employment and earnings. Franklin (1976) found that changes in the SGA level in 1966 and 1968 had little effect on increasing the labor force participation rate of beneficiaries. In follow-up work, Franklin and Hennessey (1979) found that increases in 1966, 1968, and 1974 were not followed by increases in earnings among beneficiaries. They posited that because median annual earnings were so far below annualized SGA, the changes affected work incentives for only a few beneficiaries.

A more recent report by the Government Accountability Office (GAO) also found that SGA level increases affect the earnings of only a small portion of beneficiaries (2002). Looking from 1985 to 1997 , the GAO report found that only 1 percent of all beneficiaries, and only 7.4 percent of beneficiaries who worked in a given year, had earnings greater than 75 percent of the (annualized) level of SGA. In other words, SGA mattered little for most beneficiaries. Following beneficiaries over time, the report found that of those who earned near the SGA level in a given year, most had substantial declines in earnings over time. However, about 13 percent who had earnings near the SGA level in 1985 had earnings close to the SGA level a decade later, providing some evidence that workers with higher earnings may respond to increases in the SGA and may engage in parking behavior. However, this evidence is not definitive-it is not known what share of those earning close to the SGA level would have had higher earnings if SGA had not been higher. Recognizing the limitations of the data in measuring the effect of the SGA level on earnings, the GAO report called for more research before drawing conclusive findings.

One reason the existing literature has found little evidence of the impact of increases in the SGA level on earnings might be that earlier studies examined all DI beneficiaries, including blind 
beneficiaries, whose earnings were not subject to the same SGA earnings limit, as well as those who had not completed their TWP. The incentive to restrain earnings really begins after individuals complete their TWP—but many beneficiaries who return to work never complete their TWP. Thus, increases in the SGA level matter very little for a large fraction of DI beneficiaries. Indeed, Franklin (1976) noted that the TWP had more impact on beneficiaries' attempts to work than the SGA level did, though clearly the interaction of the two was also important.

Previous studies also have not allowed for different effects of an increase in the level of SGA based on the earnings of beneficiaries prior to the change. In theory, not only might an increase in the SGA induce those with earnings below that level to increase their earnings, it could also induce some in the high-earnings group to reduce their earnings. These two changes can have opposing effects on the average level of earnings before and after the SGA increase, which might explain the absence of a substantial impact on the average earnings of beneficiaries in earlier studies 


\section{DATA AND SAMPLE DESCRIPTION}

Our analysis sample was drawn from the 2007 Ticket Research File (TRF07), which contains longitudinal SSA administrative data on all working-age beneficiaries who participated in the DI or Supplemental Security Income (SSI) programs for at least one month between January 1996 and December 2007. The TRF contains demographic information about beneficiaries as well as a monthly history of their DI and SSI benefit receipt, any time spent off of the disability rolls, use of work incentives (including the month of TWP completion), and many other variables generated from SSA administrative records. Data from the TRF were merged with annual earnings records contained in SSA's Master Earnings File (MEF) for several years before and after TWP completion.

The key outcomes in our analysis are annual earnings and percent of months in a year spent off the DI rolls for work in a calendar year. Nominal annual earnings were converted to monthly amounts by dividing the annual amount by 12 , for purposes of comparison with the monthly SGA amount. The percent of the months in a year off the rolls for work is based on a monthly variable contained in the TRF, known as the "left due to work (LDW)" indicator. This variable identifies months in which benefits were suspended or terminated because of earnings above SGA.

Using the TRF, we identified 373,679 DI beneficiaries who completed their TWP between January 1996 and December 2000. We excluded 50,003 whose birth date indicated they were under the age of 18 or over age 59 at the end of the calendar year during which they completed their TWP, who had died in the five calendar years following TWP completion, or who had inconsistent data related to their initial DI entitlement and TWP completion dates. This left a final sample of 323,676, 
or 87 percent of all TWP completers during the period. Of this sample, 2.2 percent $(6,612$ beneficiaries) were identified as being subject to the blind SGA. ${ }^{2}$

The size of annual TWP completer cohorts increased steadily from 1996 through 2000, peaking at just over 75,000 in 2000 (Table IV.1). ${ }^{3}$ Understanding differences in the demographics of TWP completer cohorts is important in assessing the extent to which observed changes in outcomes might reflect compositional differences in the cohorts as opposed to impacts of the SGA increase. The demographic profile of TWP completer cohorts from 1996 to 2000 was relatively constant, suggesting that changes we observe are unlikely to solely reflect changing demographics of TWP completers. Later cohorts, however, were somewhat more likely to be over 40 years old, female, non-Caucasian, and have certain primary disabling conditions such as back problems and major affective disorders. This generally mirrors the changing demographic profile of all DI beneficiaries during this period (Appendix Table 1).

\footnotetext{
2 To identify blind individuals, we used a variable in the administrative records indicating the date a person was determined to be blind by SSA for purposes of determining SGA. It is possible that some of those classified as nonblind for our analysis were blind but had not been determined to be blind for SGA purposes. SSA does not determine the blind status of a beneficiary unless there is an administrative reason to do so. Determination of the SGA amount provides a reason for those who work, so our expectation is that there are few blind beneficiaries among the non-blind TWP completers.

${ }^{3}$ In 2001, the number of TWP completers fell to just over 45,000. The reason for this precipitous decline is the change in the TWP earnings limit in that year from $\$ 200$ to $\$ 500$, as previously described. This is an important reason to exclude the 2001 and later TWP completer cohorts from the analysis; they are not comparable to the earlier cohorts because far fewer of them had average monthly earnings below $\$ 500$ during the TWP year. The likely effects of the 2001 recession on beneficiary earnings are a second reason to exclude later cohorts (see Stapleton, Liu, Phelps and Prenovitz, forthcoming).
} 
Table IV.1 Demographic Profile of Non-blind TWP Completers, 1996-2000

\begin{tabular}{|c|c|c|c|c|c|}
\hline & 1996 & 1997 & 1998 & 1999 & 2000 \\
\hline Sample Size & 52,490 & 59,039 & 64,475 & 67,122 & 73,483 \\
\hline $\begin{array}{l}\text { Age (\%) } \\
\text { Under } 30 \\
30-39 \\
40-49 \\
50-59\end{array}$ & $\begin{array}{l}21.1 \\
32.9 \\
29.1 \\
16.9\end{array}$ & $\begin{array}{l}19.9 \\
31.9 \\
29.7 \\
18.5\end{array}$ & $\begin{array}{l}19.3 \\
31.0 \\
30.2 \\
19.5\end{array}$ & $\begin{array}{l}19.1 \\
29.6 \\
31.3 \\
19.9\end{array}$ & $\begin{array}{l}19.0 \\
27.6 \\
31.8 \\
21.6\end{array}$ \\
\hline $\begin{array}{l}\text { Sex (\%) } \\
\text { Male } \\
\text { Female } \\
\text { Missing }\end{array}$ & $\begin{array}{r}57.4 \\
42.6 \\
0.0\end{array}$ & $\begin{array}{r}56.3 \\
43.6 \\
0.0\end{array}$ & $\begin{array}{r}55.5 \\
44.5 \\
0.0\end{array}$ & $\begin{array}{r}54.2 \\
45.8 \\
0.0\end{array}$ & $\begin{array}{r}53.4 \\
46.6 \\
0.0\end{array}$ \\
\hline $\begin{array}{l}\text { Race (\%) } \\
\text { Caucasian } \\
\text { African-American } \\
\text { Hispanic } \\
\text { Other } \\
\text { Missing }\end{array}$ & $\begin{array}{r}71.7 \\
20.0 \\
3.9 \\
2.5 \\
1.9\end{array}$ & $\begin{array}{r}70.8 \\
20.9 \\
4.1 \\
2.4 \\
1.8\end{array}$ & $\begin{array}{r}70.3 \\
21.0 \\
4.4 \\
2.6 \\
1.7\end{array}$ & $\begin{array}{r}69.6 \\
21.7 \\
4.5 \\
2.6 \\
1.6\end{array}$ & $\begin{array}{r}69.3 \\
21.6 \\
4.7 \\
2.7 \\
1.7\end{array}$ \\
\hline $\begin{array}{l}\text { Primary Disabling Condition (\%) } \\
\text { Schizophrenia or psychoses; anxiety and } \\
\text { neurotic disorders; other mental disorders } \\
\text { Major affective disorders } \\
\text { Mental retardation } \\
\text { Musculoskeletal system and back disorders } \\
\text { Injuries } \\
\text { Nervous system } \\
\text { Circulatory system } \\
\text { Neoplasms } \\
\text { Endocrine/nutritional } \\
\text { Other (known) } \\
\text { Other (unknown) }\end{array}$ & $\begin{array}{r}11.9 \\
10.4 \\
8.9 \\
4.4 \\
4.1 \\
3.1 \\
2.2 \\
2.2 \\
38.4 \\
0.3\end{array}$ & $\begin{array}{r}12.7 \\
10.5 \\
9.0 \\
4.1 \\
4.0 \\
3.3 \\
2.3 \\
2.5 \\
37.7 \\
0.2\end{array}$ & $\begin{array}{r}13.3 \\
10.4 \\
9.7 \\
4.2 \\
4.2 \\
3.2 \\
2.3 \\
2.7 \\
36.3 \\
0.2\end{array}$ & $\begin{array}{r}13.9 \\
10.7 \\
9.9 \\
4.1 \\
4.2 \\
3.2 \\
2.5 \\
2.9 \\
34.9 \\
0.2\end{array}$ & $\begin{array}{r}14.1 \\
10.3 \\
10.7 \\
4.0 \\
4.3 \\
3.3 \\
2.4 \\
2.8 \\
34.1 \\
0.1\end{array}$ \\
\hline $\begin{array}{l}\text { Education (\%) } \\
0 \text { to } 8 \text { years } \\
9 \text { to } 11 \text { years } \\
12 \text { years } \\
13-15 \text { years } \\
16 \text { or more years } \\
\text { Missing }\end{array}$ & $\begin{array}{r}3.7 \\
9.3 \\
28.9 \\
8.2 \\
5.8 \\
44.1\end{array}$ & $\begin{array}{r}3.8 \\
9.4 \\
28.9 \\
8.1 \\
5.7 \\
44.0\end{array}$ & $\begin{array}{r}3.8 \\
9.3 \\
27.8 \\
8.3 \\
5.6 \\
45.2\end{array}$ & $\begin{array}{r}3.4 \\
8.9 \\
26.8 \\
8.3 \\
5.5 \\
47.0\end{array}$ & $\begin{array}{r}3.3 \\
8.4 \\
25.9 \\
8.5 \\
5.3 \\
48.6\end{array}$ \\
\hline Concurrent (DI and SSI) beneficiary (\%) & 10.2 & 10.3 & 10.2 & 10.4 & 9.2 \\
\hline
\end{tabular}

Source: $\quad$ SSA's 2007 TRF.

Note: $\quad$ Other known primary disabling conditions include visual impairments, disorders and diseases of the genitourinary system, severe hearing impairment, HIV/AIDS, digestive system, respiratory system, blood/blood-forming diseases, and infectious/parasitic diseases. Each of these categories included fewer than 2 percent of TWP completers in 1996. 
This page has been left blank for double-sided copying. 


\section{METHODS}

We use a DD strategy to estimate the impact of the SGA increase on the earnings distribution and months off the rolls for work of non-blind TWP completers in their second year after TWP completion. ${ }^{4}$ We examine the impact of SGA on the entire distribution of earnings because, as described previously, we expect the increase in the SGA level to induce increases in earnings for some of those who would otherwise have monthly earnings below the old SGA level (nominally $\$ 500$ ), and induce reductions for some of those who would otherwise have earnings above the new SGA level (nominally \$700).

We also estimate the impact on mean earnings and on the percentage of months off the rolls for work, both in total and conditional on the earnings category in the TWP year. The conditional estimates are produced to verify that the impacts differ for low and high earners. Our expectation is that those with earnings near the old SGA amount in the TWP year are the ones most likely to increase their earnings as a result of the SGA increase, and those with TWP-year earnings above that level are most likely to reduce their earnings and their months off the rolls for work because of the SGA increase.

For each outcome, we calculated for each cohort the change from the year of TWP completion to two years later. We then compared this difference across cohorts, initially starting with all annual cohorts of non-blind TWP completers from 1996 to 2000. For the 1996 cohort, the SGA level is at the old $\$ 500$ level in both years. For both the 1997 and 1998 cohorts, the two years straddle the change in level, but the change occurred halfway during the second of the two years for the 1997 cohort. For about half of the 1999 cohort and the entire 2000 cohort, the SGA level was already at

\footnotetext{
4 As mentioned previously, our analysis to date has not controlled for demographic differences across TWP completer cohorts, but will do so in the future.
} 
the higher level when they completed the TWP. Because the earnings data are annual and the SGA level increased in the middle of 1999, a comparison of changes in earnings from the TWP year to two years later for the 1998 and 1996 cohorts is the most direct way to estimate the effect of a large, full-year change in the SGA level on full-year earnings.

We present estimates using the 1996 and 1998 cohorts of the following form:

$$
\mathrm{Y}_{\mathrm{it}}=\mathrm{a}_{\mathrm{i}}+\mathrm{bD}_{\mathrm{t}}+\mathrm{c} \mathrm{C}_{\mathrm{i}}+\mathrm{g} \mathrm{C}_{\mathrm{i}} \mathrm{D}_{\mathrm{t}}+\mathrm{mX}_{\mathrm{i}}+\mathrm{e}_{\mathrm{it}}
$$

$D_{t}$ is an indicator variable for the second year after TWP completion and $C_{i}$ is an indicator for the 1998 cohort. The coefficient of interest in this model is g, the DD estimate of the change for the 1998 cohort two years after TWP completion relative to the similar change for the 1998 cohort. X is a vector of individual characteristics in the year of TWP completion as shown in Table IV.1, plus a set of indicator variables for the calendar month of TWP completion. ${ }^{5}$

Like other DD estimators, the validity of our analysis relies on the assumption that the cohorts subject to the change in the level of SGA would have behaved similarly to the cohorts not subject to the change, and that the trend in outcomes across these cohorts would have been the same if not for the change in SGA (Imbens and Wooldridge 2007). In the next section, we assess this assumption for the 1996 and 1998 non-blind cohorts. For this study we also considered using contemporaneous blind TWP completer cohorts as comparison groups for the TWP completer cohorts, but comparisons of earnings for the blind and non-blind cohorts prior to the increase in the non-blind SGA level demonstrated that blind cohorts were an inadequate comparison group. ${ }^{6}$

\footnotetext{
5 Table IV.1 contains an aggregated set of primary disabling impairments; we included indicator variables for a broader set of conditions in our models.

${ }^{6}$ We also found substantive differences in the demographic characteristics of the blind and non-blind cohorts. The most notable difference, in addition to the obvious difference in primary impairments, is that blind beneficiaries in each cohort tended to be younger than their non-blind counterparts; for instance, the percentage of the 2000 non-blind cohort age 30 to 39 was 8 percentage points higher than for the 2000 non-blind cohort.
} 


\section{ASSESSING THE VALIDITY OF THE DD APPROACH: EARNINGS DISTRIBUTIONS BY COHORT AND TIME RELATIVE TO TWP COMPLETION}

This section examines the suitability of using cohorts from 1996 to 2000 in the application of the DD method. We first compare the distributions of average monthly earnings in the TWP year over the range around the old and new SGA, from $\$ 300$ to $\$ 1,100$. The purpose of this comparison is to determine whether TWP-year distributions for the years prior to the SGA increase (1996 to 1998) are sufficiently comparable to serve as the base year for the DD analysis. We also use this comparison to assess whether there is any evidence of a change in the TWP year distribution after the mid-1999 increase in SGA that might make the 1999 and 2000 cohorts unsuitable for the DD analysis. We then extend the comparisons to the first and second year after TWP completion, where we expect to see evidence of the SGA increase for the 1998 through 2000 cohorts, but also eventually expect to see effects of the 2001 recession that might be confounded with the effects of the SGA level increase. We apply the DD estimator to changes in the average annual earnings distribution from the TWP year to the year after TWP for the 1996 and 1997 cohorts, neither of which experienced an increase in the SGA level from the TWP year to the next year, to test whether the DD estimator might produce spurious results because of wage inflation or other potentially confounding factors. We conclude the section by comparing TWP-year estimates of months off the rolls for work, by earnings range, for the 1996 and 1998 cohorts, the base for the estimates used in the DD estimator for months off the rolls.

In the TWP completion year, the distributions for successive cohorts shift downward in a uniform manner over the relevant range, with the exception of that for the 2000 cohort (Figure VI.1). It seems likely that the shift in each year reflects our use of nominal earnings. This was a period of economic expansion, so presumably each successive cohort, as a group, had somewhat higher nominal wages. There is a downward shift for the 2000 cohort relative to the previous cohort, but it is distinctly different than between the early cohorts; it is much larger at earnings levels below 
the old SGA and much smaller for earnings levels above the new SGA. This pattern seems likely to reflect the fact that beneficiaries who complete the TWP early in a calendar year face benefit suspension if they engage in SGA for more than three months (i.e., the grace period months) later in the year. Thus, for at least part of the TWP year they have an incentive to keep earnings below SGA. Hence, the higher SGA faced by the 2000 cohort throughout its TWP year might have reduced the percentage with earnings below the old SGA and increased the percentage with earnings above the new SGA, as predicted in Figure II.1.

Figure VI.1 Cumulative Distribution of Monthly Earnings in the TWP Completion Year, 1996-2000 Cohorts

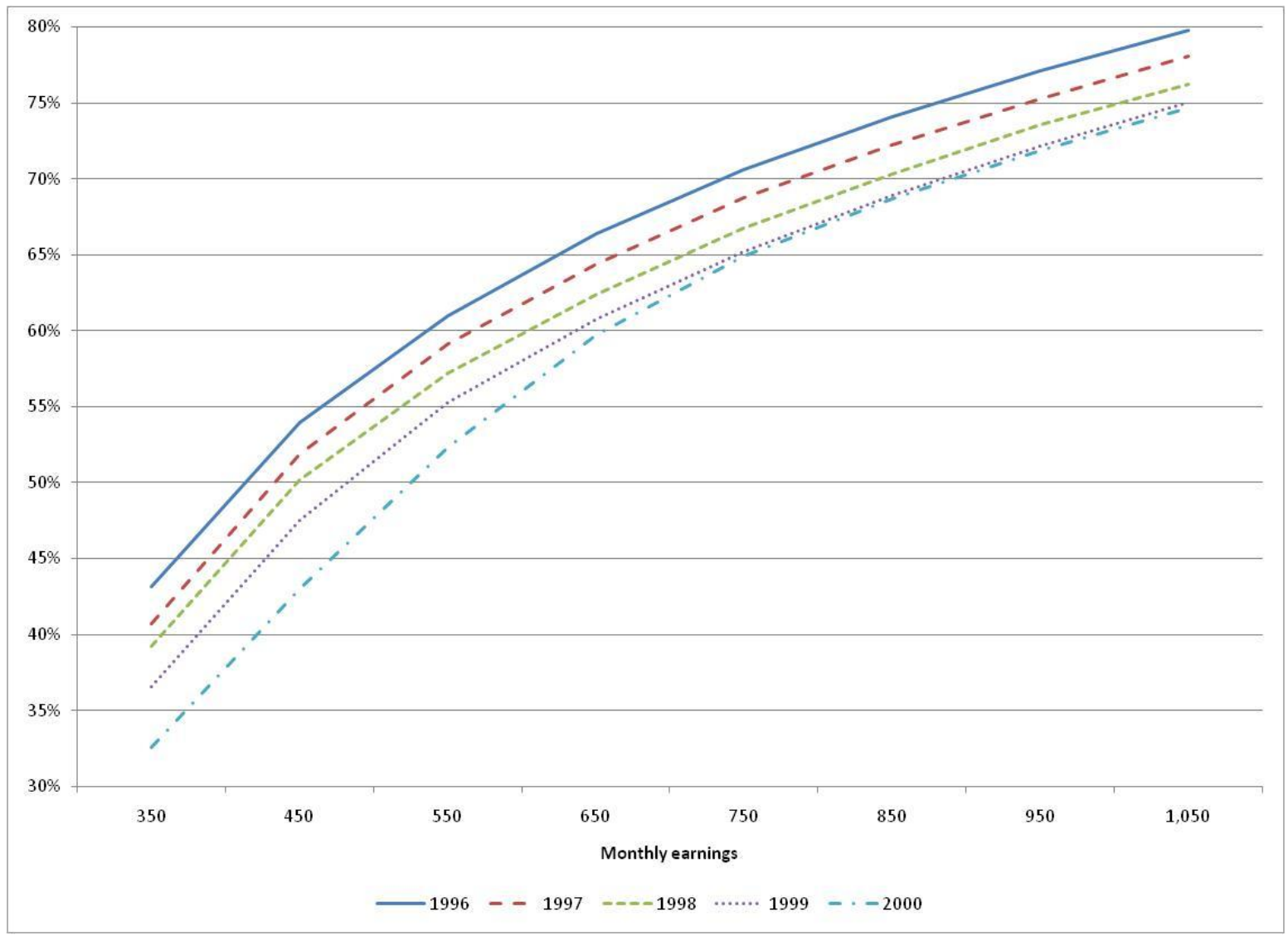

\section{Source: $\quad$ SSA's TRF07 and MEF}

Note: Nominal earnings in $\$ 100$ intervals; dollar value denoted is the midpoint of the interval. Level differences across the cohorts reflect our use of nominal earnings; when earnings were adjusted by the contemporaneous average wage index (AWI), these level differences disappeared. 
For the first year after TWP completion, the distributions for the 1997 and 1998 cohort shift downward in a uniform manner relative to the distribution for the 1996 cohort over the range of earnings around SGA, even though the higher SGA applies to the 1998 cohort for half of the year. For the 1999 and, especially the 2000 cohort, the downward shift is not uniform; in fact, relative to the 1999 cohort, the distribution for the 2000 cohort shifts upward for earnings above the old SGA value and is even higher than the distribution for the 1998 cohort for earnings above the new SGA. The 2000 cohort's earnings are for calendar year 2001, so it might be that its shape relative to the earlier cohorts partly reflects the effect of the 2001 recession.

For the second year after TWP completion, the downward shift for the 1997 cohort is uniform relative to that of the 1996 cohort, but the downward shift for the 1998 cohort is much smaller above the new SGA than it is below the old SGA, consistent with our expectations. The 1999 cohort's distribution is very similar to that for the 1998 cohort, but actually lies slightly above the latter for earnings above the new SGA. The distribution for the 2000 cohort is remarkable in that it shifts upward relative to that for the 1999 cohort over the entire range around SGA. The distributions for the 1999 and 2000 cohorts are for calendar years 2001 and 2002, respectively; it seems likely that any effect of the 1999 SGA increase on their distributions is confounded with the effects of the 2001 recession. This is the obvious explanation for the shift observed for the 2000 cohort in the second year after TWP completion. ${ }^{7,8}$ For this reason, we exclude these later cohorts from the DD analysis.

${ }^{7}$ Appendix Figure 3 contains the full distribution for the 1996 cohort in the TWP year and the two years after, for earnings up to $\$ 5,000$ per month. Approximately eight percent of each cohort did not have earnings in the TWP completion year, likely a data anomaly or earnings reporting error. Approximately 15 percent did not have earnings in the year after TWP completion and 22 percent two years after. This pattern was nearly identical in the 1997 and 1998 cohorts. 
We conclude that the TWP-year distributions for the 1996 through 1998 cohorts are quite comparable, apart from the small, similar effects of wage growth. We further conclude that crosscohort differences in the two years after the TWP completion year for these cohorts also reflect the effects of wage growth, but that those for the 1997 and, especially, the 1998 cohorts start to reflect the effects of the 1999 SGA increase. Cross-cohort differences for the 1999 and, especially, the 2000 cohorts presumably reflect the effects of the increase in the SGA level, but starting in calendar year 2001 also appear to reflect the effects of the 2001 recession.

The DD methodology potentially controls for wage growth for periods when wage growth is steady, because it compares two-year changes in wages for the successive cohorts. If the effect of wage growth on earnings from the TWP year to two years later is comparable across the entire earnings range, and especially the range around the old and new SGA levels, the DD estimator will successfully control for it.

To test whether the DD estimator successfully controls for the potentially confounding effect of different wage growth or other factors that might affect the earnings distributions of successive cohorts differently, we applied the estimator to the 1996 and 1997 cohorts for changes in the earnings distributions from the TWP completion year to the year after TWP completion. Because neither cohort experienced a change in the SGA level between these two years, the DD estimates in every earnings range should be close to zero if the estimator successfully controls for wage growth and any other potentially confounding factors. We also applied the DD estimator to earnings adjusted by the AWI — the same wage-growth index applied to the SGA level after 1999—-to see if that adjustment would reduce any effects of potentially confounding factors in this period.

(continued)

${ }^{8}$ Part of the difference could also reflect changing demographics across TWP completer cohorts, though we would expect that if that were the case, the distributions in the TWP completion year would not look so similar across the cohorts. Our future analysis to control for demographics will take this into account. 
The results are summarized in Table VI.1. When we use nominal earnings, the point estimates for effect of confounding factors on the percentage with earnings in each earnings interval in the year after TWP completion are small and not related to the level of earnings. The point estimate for the interval from $\$ 200$ to $\$ 500$ is largest in magnitude, but is only -0.3 percentage points, less than one percent of the 1997 cohort percentage in that category. The point estimate in the critical range between the old and new SGA is 0.0 . When we adjust earnings by the AWI, we find much more substantial estimates in all intervals except the interval from $\$ 0$ to $\$ 199$; the largest estimate is for the interval of $\$ 1,000$ or more- 0.5 percentage points. Further, there is a pattern in the AWI-adjusted estimates: negative estimates for the intervals below $\$ 500$ and positive estimates for those above $\$ 500$.

Table VI.1 DD Estimates for the Effects of Potentially Confounding Factors on the Earnings in the First Year after TWP Completion, 1997 Versus 1996 Cohort

\begin{tabular}{|c|c|c|c|c|c|c|}
\hline \multirow[b]{2}{*}{$\begin{array}{l}\text { Earnings } \\
\text { Category }\end{array}$} & \multicolumn{2}{|c|}{$\begin{array}{c}\text { Percent of Cohort } \\
\text { with Earnings in } \\
\text { Category, Year of TWP } \\
\text { Completion }\end{array}$} & \multicolumn{2}{|c|}{$\begin{array}{c}\text { Percent of Cohort with } \\
\text { Earnings in Category, } \\
\text { First Year after TWP } \\
\text { Completion }\end{array}$} & \multicolumn{2}{|c|}{$\begin{array}{l}\text { DD Estimate of the Effects } \\
\text { of Wage Growth and Other } \\
\text { Factors (Percentage Points) }\end{array}$} \\
\hline & $\begin{array}{l}1996 \\
\text { Cohort }\end{array}$ & $\begin{array}{l}1997 \\
\text { Cohort }\end{array}$ & $\begin{array}{c}1996 \\
\text { Cohort }\end{array}$ & $\begin{array}{l}1997 \\
\text { Cohort }\end{array}$ & Nominal & $\begin{array}{c}\text { AWl- } \\
\text { Adjusted }\end{array}$ \\
\hline$\$ 0$ to $\$ 199$ & 17.4 & 16.2 & 30.4 & 29.4 & 0.2 & -0.1 \\
\hline$\$ 200$ to $\$ 500$ & 36.6 & 35.7 & 26.9 & 25.8 & -0.2 & -0.6 \\
\hline$\$ 500$ to $\$ 699$ & 12.4 & 12.5 & 9.2 & 9.3 & 0.0 & -0.1 \\
\hline$\$ 700$ to $\$ 999$ & 10.7 & 10.9 & 8.0 & 8.2 & 0.1 & 0.2 \\
\hline$\$ 1,000$ or more & 22.9 & 24.7 & 25.5 & 27.3 & -0.1 & 0.5 \\
\hline
\end{tabular}

Source: $\quad$ SSA'S TRF07 and MEF

Note: $\quad$ DD estimates regression-adjusted for control for differences in 1996 and 1997 cohorts. AWIadjusted earnings calculated using contemporaneous AWI value in each year.

We conclude that the DD estimator applied to nominal wages during this period adequately controls for the effect of wage growth and other potentially confounding factors but it does not do so when it is applied to AWI-adjusted earnings. The results for AWI-adjusted earnings might occur 
because the AWI is a poor measure of wage growth in the types of jobs typically held by beneficiaries, as is suggested by previous evidence. ${ }^{9}$

Turning to percent of months during the TWP completion year spent off the rolls for work, we see that in most ranges of earnings, the values for the 1996 and 1998 cohorts are similar (Figure VI.2). The pattern in both years behaves according to expectations; as average monthly earnings during a year increase, the likelihood of spending more of the year off the rolls increases, reflecting more months with earnings above SGA. There are small differences within TWP-year earnings categories, which might reflect wage growth or other factors. The largest difference, for those with average monthly earnings in excess of $\$ 1,000$, is only 0.2 months. Hence, we conclude that months off the rolls during the TWP year are a strong base for the DD estimator for this variable.

9 Autor and Duggan (2006) have previously shown that the growth rate of wages for jobs held by workers before they applied for benefits during this period was lower than the AWI. 
Figure VI.2 Mean Months off the Rolls for Work in TWP Completion Year, by Earnings Category, 1996 and 1998 Cohorts

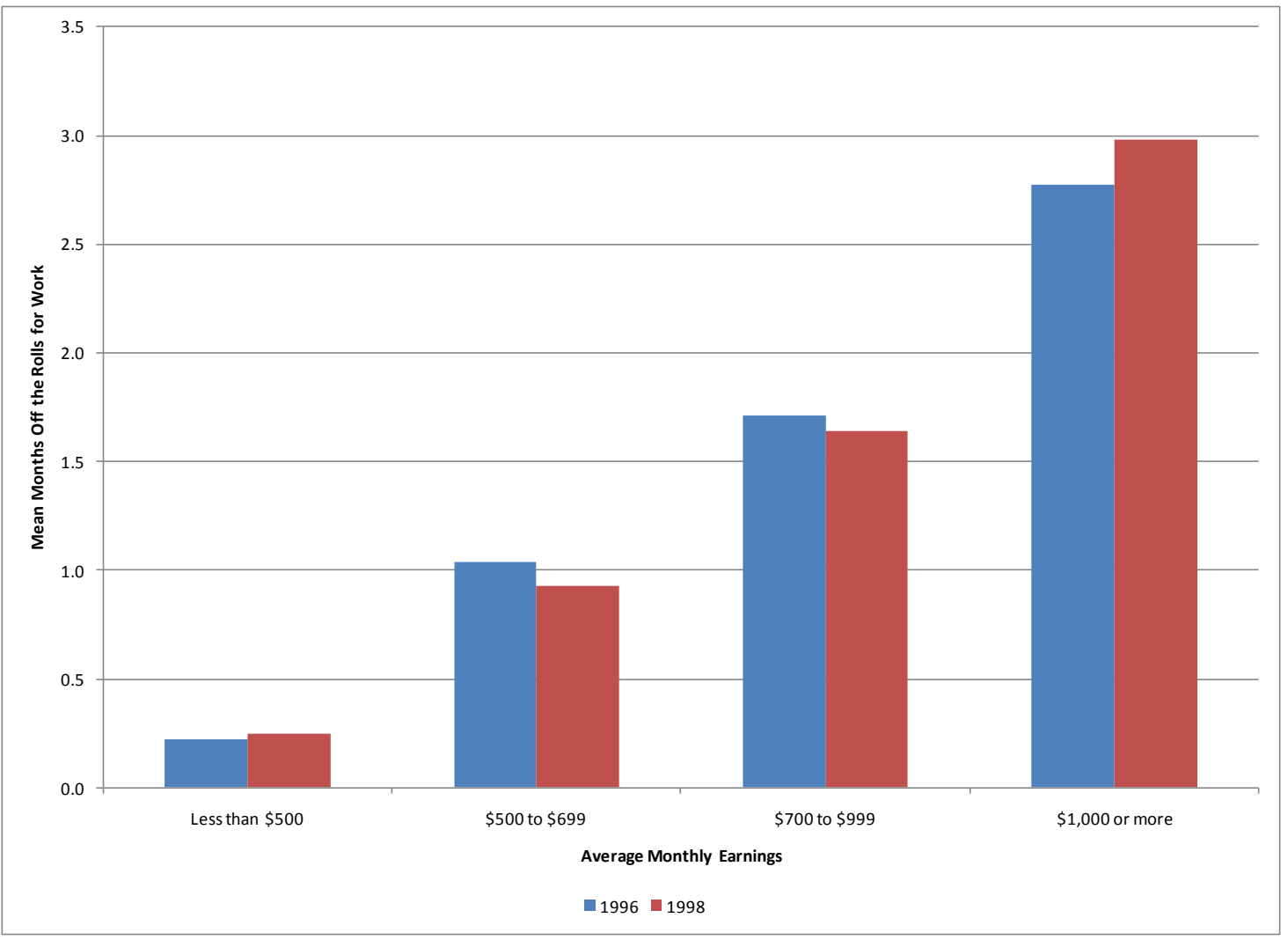

Source: $\quad$ SSA's TRF07 and MEF 
This page has been left blank for double-sided copying. 


\section{RESULTS}

Using the 1996 and 1998 cohorts of non-blind TWP completers, we calculate DD estimates for impacts in the second year after TWP completion. That is, we compare changes in outcome variables from the TWP year to two years after the TWP year for these two cohorts. For the 1996 cohort, both years were prior to the July 1999 change in the non-blind SGA limit; hence, the change for this group represents what happens when there is no change in the nominal value of SGA. For the 1998 cohort, nominal non-blind SGA in the second year after the TWP completion is $\$ 200$ higher than in the TWP year.

We first present DD estimates of the impact of the increase in the SGA level on the percentage of the 1998 TWP cohort with average monthly earnings within specified intervals (Figure VII.1 and Table VII.1), before turning to estimates for the impacts on mean earnings (Table VII.2) and the percentage of months off the rolls for work (Table VII.3). All of the estimates are for impacts in the second year after TWP completion. In each case, we present unadjusted group means, but the DD estimates are regression-adjusted, controlling for the variables described previously. The regressionadjusted values tended to be the same as the unadjusted estimates to the third decimal place or more, suggesting that difference in characteristics between the 1996 and 1998 cohorts did not significantly affect their outcomes.

DD estimates for the percentage with monthly earnings within intervals indicate that the $\$ 200$ increase in SGA resulted in a reduction in the percentage with earnings below $\$ 500$, although not in every $\$ 100$ interval; an increase in the percentage with earnings between $\$ 500$ and $\$ 700$; and a decline in the percentage with earnings above $\$ 700$ (Figure VI.1, Table VII.1). The total reduction in the range below $\$ 500$ is 1.0 percentage points, the total decline for the range above $\$ 700$ is 1.2 percentage points, and, tautologically, the total increase for the percentage between $\$ 500$ and $\$ 700$ is the sum of these two: 2.2 percentage points. 
These estimates imply that, were it not for the increase in the SGA level, 1.0 percent of the 1998 cohort would have kept their average monthly earnings in this year below $\$ 500$ and that 1.2 percent of the cohort would have had earnings above $\$ 700$. Both are evidence of parking. They also suggest that between 1.2 and 2.2 percent of beneficiaries in the cohort -774 to 1,418 beneficiariesparked their earnings in this interval during the second year after TWP completion. Both bounds assume that the 1.2 percent of beneficiaries induced to reduce their earnings to less than $\$ 700$ would have reduced them less if the SGA level had been increased more. The lower bound assumes that those induced to increase their earnings above $\$ 500$ because of the SGA increase would not have increased them further even if the SGA level were increased further, while the upper bound assumes that they all would have increased their earnings more.

Figure VII.1 DD Estimates of the Impact of the 1999 SGA Increase on the Percentage of the 1998 TWP Completers Within Earnings Intervals in the Second Year after TWP Completion

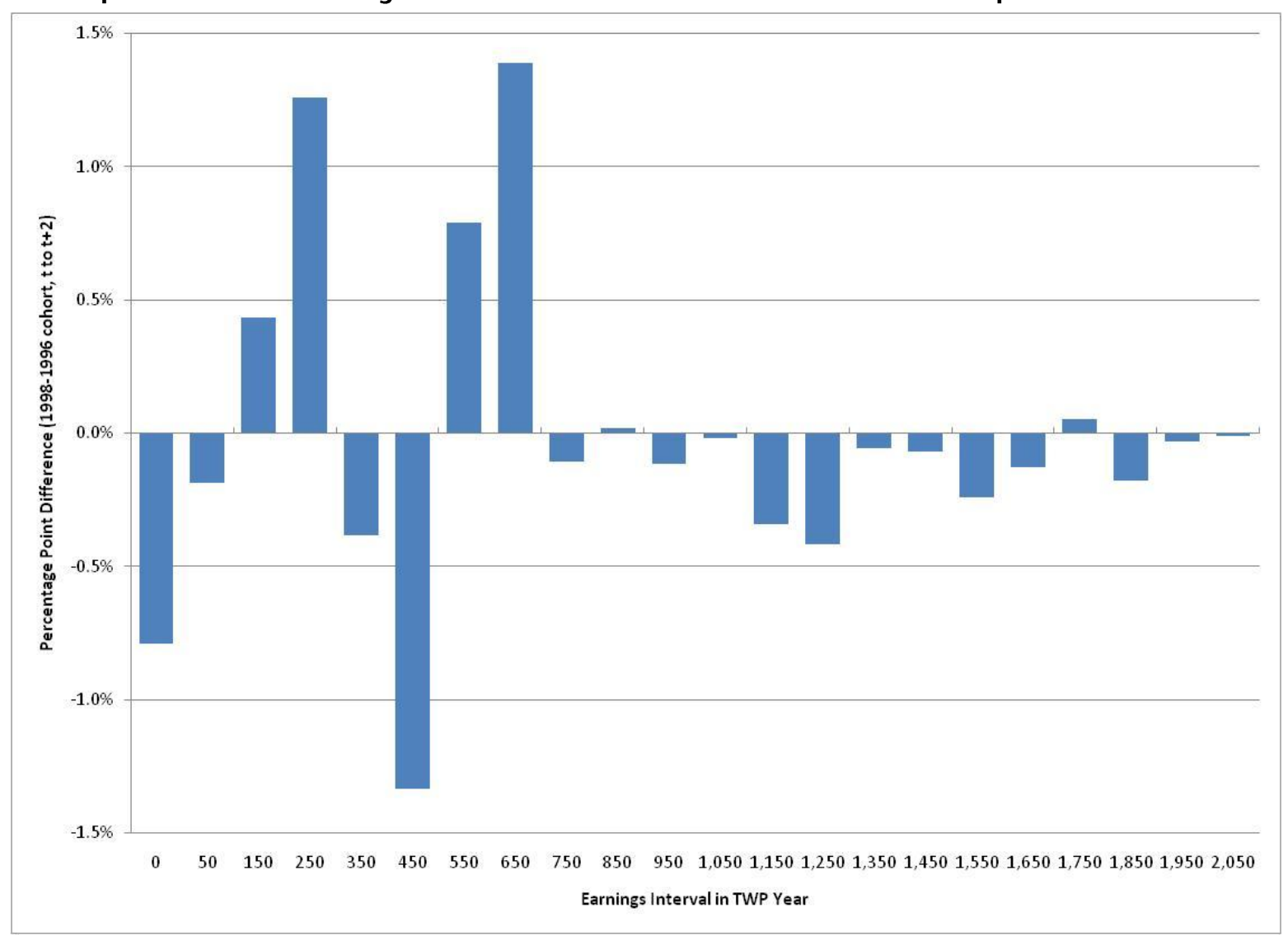

Source: $\quad$ SSA's TRF07 and MEF.

Note: Nominal earnings in $\$ 100$ intervals; dollar value denoted is the midpoint of the interval. 
Table VII.1 DD Estimates for the Effects of the 1999 SGA Increase on Earnings in the Second Year after TWP Completion

\begin{tabular}{|c|c|c|c|c|c|c|}
\hline \multirow[b]{2}{*}{$\begin{array}{l}\text { Earnings } \\
\text { Category }\end{array}$} & \multicolumn{2}{|c|}{$\begin{array}{c}\text { Percent of Cohort with } \\
\text { Earnings in Category, } \\
\text { Year of TWP } \\
\text { Completion }\end{array}$} & \multicolumn{2}{|c|}{$\begin{array}{c}\text { Percent of Cohort with } \\
\text { Earnings in Category, } \\
\text { Second Year after TWP } \\
\text { Completion }\end{array}$} & \multicolumn{2}{|c|}{$\begin{array}{l}\text { DD Estimate of the Effect } \\
\text { of the SGA Increase }\end{array}$} \\
\hline & $\begin{array}{l}1996 \\
\text { Cohort }\end{array}$ & $\begin{array}{l}1998 \\
\text { Cohort }\end{array}$ & $\begin{array}{l}1996 \\
\text { Cohort }\end{array}$ & $\begin{array}{c}1998 \\
\text { Cohort }\end{array}$ & $\begin{array}{c}\text { Estimate } \\
\text { (Percentage } \\
\text { Points) }\end{array}$ & $\begin{array}{l}\text { Percentage } \\
\text { DD Estimate }\end{array}$ \\
\hline$\$ 0$ to $\$ 199$ & 17.4 & 16.2 & 36.7 & 35.0 & -0.5 & -1.4 \\
\hline$\$ 200$ to $\$ 500$ & 36.6 & 34.0 & 22.4 & 19.3 & -0.5 & -2.2 \\
\hline$\$ 500$ to $\$ 699$ & 12.4 & 12.2 & 7.8 & 9.8 & 2.2 & 28.2 \\
\hline$\$ 700$ to $\$ 999$ & 10.7 & 11.1 & 7.0 & 7.1 & -0.2 & -2.9 \\
\hline$\$ 1,000$ or more & 22.9 & 26.5 & 26.2 & 28.8 & -1.0 & -3.8 \\
\hline
\end{tabular}

Source: $\quad$ SSA's TRF07 and MEF

Note: $\quad$ DD estimates regression-adjusted for control for differences in 1996 and 1998 cohorts. The percentage effect (last column) is the estimate from the previous column divided by the mean months off the rolls in 1998 of the 1996 TWP completers within the TWP-year earnings group.

Table VII.2 DD Estimate of Impact on Mean Monthly Earnings Two Years after TWP Completion, by Earnings Interval in TWP Completion Year

\begin{tabular}{|c|c|c|c|c|c|c|}
\hline & \multicolumn{2}{|c|}{$\begin{array}{l}\text { Percentage in } \\
\text { Category }\end{array}$} & \multicolumn{2}{|c|}{$\begin{array}{l}\text { Change in Mean } \\
\text { Earnings }(\$), \text { TWP Year } \\
\text { to Two Years Later }\end{array}$} & \multirow{2}{*}{$\begin{array}{c}\text { DD Estimate } \\
\text { (\$ per } \\
\text { month) } \\
\text { (t-statistic) }\end{array}$} & \multirow[b]{2}{*}{$\begin{array}{l}\text { Percentage } \\
\text { DD Estimate }\end{array}$} \\
\hline & $\begin{array}{c}1996 \\
\text { Cohort }\end{array}$ & $\begin{array}{l}1998 \\
\text { Cohort }\end{array}$ & $\begin{array}{c}1996 \\
\text { Cohort }\end{array}$ & $\begin{array}{c}1998 \\
\text { Cohort }\end{array}$ & & \\
\hline Total & 100.0 & 100.0 & 44.04 & 47.92 & $\begin{array}{c}3.89 \\
(034)\end{array}$ & 0.5 \\
\hline Weighted Total & 100.0 & 100.0 & 37.70 & 47.84 & $\begin{array}{l}10.14 \\
(0.96)\end{array}$ & 1.3 \\
\hline $\begin{array}{l}\text { TWP Year Earnings } \\
\text { Less than } \$ 500\end{array}$ & 54.0 & 50.2 & 98.61 & 114.60 & $\begin{array}{c}15.99 \\
(3.00)\end{array}$ & 6.3 \\
\hline$\$ 500$ to $\$ 699$ & 12.4 & 12.2 & 29.28 & 46.54 & $\begin{array}{l}17.25 \\
(1.46)\end{array}$ & 2.9 \\
\hline$\$ 700$ to $\$ 999$ & 10.7 & 11.1 & 36.29 & 54.78 & $\begin{array}{c}18.49 \\
(1.06)\end{array}$ & 2.2 \\
\hline$\$ 1,000$ or more & 22.9 & 26.5 & -73.23 & -80.92 & $\begin{array}{l}-7.69 \\
(-0.21)\end{array}$ & -0.3 \\
\hline
\end{tabular}

Source: $\quad$ SSA'S TRF07 and MEF

Note: $\quad$ DD estimates regression-adjusted to control for differences in 1996 and 1998 cohorts. Within each group, the percentage effect (last column) is the estimate from the previous column divided by the mean earnings in 2000 of the 1998 TWP completers net of the DD estimate for the group. 
Table VII.3 Estimates of the Impact on Months Off the Rolls for Work by Earnings Interval in TWP Completion Year, 1996 and 1998 TWP Completer Cohorts

\begin{tabular}{|c|c|c|c|c|c|c|}
\hline & \multicolumn{2}{|c|}{$\begin{array}{l}\text { Percent in } \\
\text { Category }\end{array}$} & \multicolumn{2}{|c|}{$\begin{array}{l}\text { Change in Mean Months Off } \\
\text { the Rolls Due to Work, TWP } \\
\text { Year to Two Years Later }\end{array}$} & \multirow{2}{*}{$\begin{array}{c}\text { DD } \\
\text { Estimate } \\
\text { (months) } \\
\text { (t-statistic) }\end{array}$} & \multirow{2}{*}{$\begin{array}{l}\text { Percentage } \\
\text { DD } \\
\text { Estimate }\end{array}$} \\
\hline & $\begin{array}{c}1996 \\
\text { Cohort }\end{array}$ & $\begin{array}{c}1998 \\
\text { Cohort }\end{array}$ & 1996 Cohort & 1998 Cohort & & \\
\hline Total & 100.0 & 100.0 & 2.62 & 2.49 & $\begin{array}{l}-0.13 \\
(-4.14)\end{array}$ & -3.5 \\
\hline Weighted Total & 100.0 & 100.0 & 2.73 & 2.49 & $\begin{array}{l}-0.24 \\
(-8.42)\end{array}$ & -6.4 \\
\hline $\begin{array}{l}\text { TWP Year Earnings } \\
\text { Less than } \$ 500\end{array}$ & 54.0 & 50.2 & 1.58 & 1.28 & $\begin{array}{l}-0.29 \\
(-9.45)\end{array}$ & -16.2 \\
\hline$\$ 500$ to $\$ 699$ & 12.4 & 12.2 & 2.79 & 2.16 & $\begin{array}{l}-0.63 \\
(-7.40)\end{array}$ & -17.1 \\
\hline$\$ 700$ to $\$ 999$ & 10.7 & 11.1 & 3.59 & 3.36 & $\begin{array}{l}-0.22 \\
(-2.18)\end{array}$ & -4.3 \\
\hline$\$ 1,000$ or more & 22.9 & 26.5 & 4.53 & 4.56 & $\begin{array}{c}0.03 \\
(0.38)\end{array}$ & 0.4 \\
\hline
\end{tabular}

Source: $\quad$ SSA's TRF07 and MEF

Note: $\quad$ DD estimates regression-adjusted to control for differences in 1996 and 1998 cohorts. Within each group, the percentage effect (last column) is the estimate from the previous column divided by the mean earnings in 2000 of the 1998 TWP completers net of the DD estimate for the group.

We find a small and statistically insignificant positive effect of less than $\$ 4$ per month on the mean earnings of all beneficiaries in the second year after TWP completion (Table VII.2). This unweighted total estimate reflects the effects of any changes in the distribution of TWP-year earnings from 1996 to 1998, which presumably are not caused by the SGA increase. We also show a weighted total estimate, based on DD estimates for the four TWP-year earnings intervals weighted by the percent of the 1998 cohort in that interval. The weighted total estimate is somewhat larger, but still small $— \$ 10$ per month—and still not statistically significant. The total impact estimate disguises statistically significant, although small, positive impacts for the 50 percent of beneficiaries with TWP-year earnings below $\$ 500$. The effect in this range was on the order of $\$ 16$ per month, or 6.3 percent of average monthly earnings in this range. We found insignificant effects of a similar magnitude for those earning between $\$ 500$ and $\$ 1,000$ in the TWP year. Even smaller and insignificant effects were found for the one-quarter with TWP-year earnings of $\$ 1,000$ or more. 
Consistent with expectations, the results show a significant negative effect of the SGA increase on the months during the second year after TWP completion that beneficiaries were off the rolls for work (Table VII.3). The weighted total DD estimate shows a statistically significant but small mean negative impact of 0.24 months, or 6.4 percent of the average number of months spent off the rolls for work by the 1998 cohort in the second year after TWP completion. The weighted total estimate was more than twice as large as the unweighted, reflecting variation in the magnitude of the effect with TWP-year earnings interval and differences between the TWP-year earnings distributions for the 1996 and 1998 cohorts. As expected, the effect was largest for those with TWP-year earnings in the range between the old and new SGA: -0.6 months, or 17.1 percent of the months that their counterparts in the 1998 TWP cohort were off the rolls in the second year after TWP completion. The negative effect for those with earnings under $\$ 500$ in the TWP year was half as large, but almost as large in percentage terms (16.2 percent). The estimates also show small but statistically significant negative effects for those with TWP-year earnings between $\$ 700$ and $\$ 1,000$. 
This page has been left blank for double-sided copying. 


\section{THE EFFECT OF ADJUSTING FOR WAGE GROWTH}

All of the results we have presented thus far for the 1998 and 1996 cohorts are based on nominal earnings, without adjustment for changes in wage growth across the cohorts. The decision to use nominal earnings rather than AWI-adjusted earnings was based on the comparison of the two versions of the estimates applied to changes in the earnings distributions for the 1997 and 1996 cohorts from the TWP year to the following year. That comparison suggested that estimates based on AWI-adjusted earnings would show systematic spurious impacts of the later increase in the SGA level, whereas the nominal version appeared to control for wage growth and any other factors that might have affected the two cohorts differently. Of course, we cannot determine that the findings from the comparison of the 1997 and 1996 cohorts for the first year after TWP completion would have been replicated for the comparison of the 1998 and 1996 cohorts for the second year after TWP completion if there had been no SGA increase. Hence, we replicated the nominal DD estimates for this period using the AWI-adjusted earnings. If there was a cohort difference in twoyear wage growth rates in the types of jobs obtained by TWP completers, and the difference in the AWI growth rates captured that difference well, the AWI-adjusted DD estimates would be preferred to the nominal estimates.

Before proceeding, it is important to consider the implications of the AWI adjustment applied to earnings on their interpretation. Because we have used the AWI to adjust earnings for wage growth, the AWI-adjusted value of SGA changes for both cohorts. ${ }^{10}$ Further, the difference between the AWI-adjusted SGA changes for the two cohorts is not quite as large as the difference between the nominal SGA changes. For the 1996 cohort, the AWI-adjusted SGA value declines by $\$ 60$ from

10 The AWI-adjusted SGA value is the nominal value divided by the AWI value for the same year and multiplied by the value for the base year. We used 2000 for the base year. Note that SSA now adjusts the SGA level by the AWI from two years prior to the current year, reflecting the lag in data availability. 
1996 to 1998; for the 1998 cohort, the AWI-adjusted SGA value increases by $\$ 135$. Hence, when earnings are adjusted by AWI, we are in effect comparing outcome changes when SGA increases by $\$ 135$ to outcomes changes when SGA decreases by $\$ 60$, so the difference in the AWI-adjusted SGA change for the two cohorts is $\$ 195$ - just slightly smaller than the $\$ 200$ difference in the nominal change. Thus, the results presented in this section should be interpreted as impacts of a $\$ 195$ increase in AWI-adjusted SGA.

DD estimates for the percentage with monthly earnings within intervals indicate that the $\$ 195$ increase in AWI-adjusted SGA shows a positive impact in the range between $\$ 500$ and $\$ 700$ of 2.0 percentage points, quite comparable to the 2.2 percentage point impact found for this interval using nominal earnings data. The results differ markedly, however, for lower and higher earnings levels. The AWI-adjusted results show a much larger decline for the percentage with earnings below $\$ 500$ (2.4 versus 1.0 percentage points) and an increase in the percentage with earnings above $\$ 700$ of 0.4 percentage points, instead of a decline of 1.2 percentage points. The latter is contrary to expectations; it is difficult to explain why the SGA increase would increase the percentage with earnings above the new SGA.

Table VIII.1 AWI-Adjusted DD Estimates for the Effects of the 1999 SGA Increase on Earnings in the Second Year after TWP Completion

\begin{tabular}{|c|c|c|c|c|c|c|}
\hline \multirow[b]{2}{*}{$\begin{array}{l}\text { Earnings } \\
\text { Category }\end{array}$} & \multicolumn{2}{|c|}{$\begin{array}{l}\text { Percent of Cohort with } \\
\text { AWI-Adjusted Earnings in } \\
\text { Category, Year of TWP } \\
\text { Completion }\end{array}$} & \multicolumn{2}{|c|}{$\begin{array}{c}\text { Percent of Cohort with } \\
\text { AWI-Adjusted } \\
\text { Earnings in Category, } \\
\text { Second Year after TWP } \\
\text { Completion }\end{array}$} & \multicolumn{2}{|c|}{$\begin{array}{l}\text { DD Estimate of the Effect } \\
\text { of the SCA Increase }\end{array}$} \\
\hline & $\begin{array}{l}1996 \\
\text { Cohort }\end{array}$ & $\begin{array}{l}1998 \\
\text { Cohort }\end{array}$ & $\begin{array}{c}1996 \\
\text { Cohort }\end{array}$ & $\begin{array}{c}1998 \\
\text { Cohort }\end{array}$ & $\begin{array}{c}\text { Estimate } \\
\text { (Percentage } \\
\text { Points) }\end{array}$ & $\begin{array}{c}\text { Percentage } \\
\text { DD } \\
\text { Estimate }\end{array}$ \\
\hline$\$ 0$ to $\$ 199$ & 15.2 & 15.5 & 36.0 & 35.6 & -0.6 & -1.8 \\
\hline$\$ 200$ to $\$ 500$ & 30.9 & 32.0 & 21.0 & 20.3 & -1.8 & -8.6 \\
\hline$\$ 500$ to $\$ 699$ & 14.7 & 13.1 & 8.8 & 9.3 & 2.0 & 23.2 \\
\hline$\$ 700$ to $\$ 999$ & 11.7 & 11.2 & 6.9 & 7.1 & 0.5 & 7.4 \\
\hline$\$ 1,000$ or more & 27.6 & 28.2 & 27.3 & 27.7 & -0.1 & -0.4 \\
\hline
\end{tabular}

Source: $\quad$ SSA'S TRF07 and MEF

Note: DD estimates regression-adjusted for control for differences in 1996 and 1998 cohorts. Earnings adjusted for wage growth to 2000 dollars using the contemporaneous AWI. 
We find no significant effect of the SGA increase on the mean earnings of all beneficiaries; the weighted total estimate is nearly identical to the unweighted total (Table VIII.2). Differences do emerge over some TWP-year earnings intervals, however. Whereas we found significant positive impacts on earnings for those with TWP-year earnings below $\$ 500$ using nominal earnings, with AWI-adjusted earnings we did not statistically significant impacts in any of the TWP-year earnings categories.

Table VIII.2 Estimates of the Mean Impact on Average Monthly Earnings by AWI-adjusted Earnings Interval in TWP Completion Year, 1996 and 1998 TWP Completer Cohorts

\begin{tabular}{|c|c|c|c|c|c|c|}
\hline & \multicolumn{2}{|c|}{ Percent in Category } & \multicolumn{2}{|c|}{$\begin{array}{c}\text { Change in Mean Earnings } \\
(\$) \text {, TWP Year to Two } \\
\text { Years Later }\end{array}$} & \multirow{2}{*}{$\begin{array}{c}\text { DD } \\
\text { Estimate } \\
\text { (months) } \\
\text { (t-statistic) }\end{array}$} & \multirow{2}{*}{$\begin{array}{c}\text { Percentage } \\
\text { DD } \\
\text { Estimate }\end{array}$} \\
\hline & $\begin{array}{c}1996 \\
\text { Cohort }\end{array}$ & $\begin{array}{c}1998 \\
\text { Cohort }\end{array}$ & $\begin{array}{c}1996 \\
\text { Cohort }\end{array}$ & $\begin{array}{c}1998 \\
\text { Cohort }\end{array}$ & & \\
\hline Total & 100.0 & 100.0 & -47.28 & -46.12 & $\begin{array}{l}1.17 \\
(0.10)\end{array}$ & 0.1 \\
\hline Weighted Total & 100.0 & 100.0 & -47.27 & -46.17 & $\begin{array}{l}1.11 \\
(0.71)\end{array}$ & 0.1 \\
\hline $\begin{array}{l}\text { TWP Year Earnings } \\
\text { Less than } \$ 500\end{array}$ & 46.1 & 47.5 & 88.23 & 86.14 & $\begin{array}{l}-2.08 \\
(-0.36)\end{array}$ & -0.6 \\
\hline$\$ 500$ to $\$ 699$ & 14.7 & 13.1 & -19.33 & -11.93 & $\begin{array}{l}7.39 \\
(0.73)\end{array}$ & 1.3 \\
\hline$\$ 700$ to $\$ 999$ & 11.7 & 11.2 & -51.54 & -36.02 & $\begin{array}{l}15.52 \\
(0.97)\end{array}$ & 2.0 \\
\hline$\$ 1,000$ or more & 27.6 & 28.2 & -286.80 & -288.97 & $\begin{array}{l}-2.17 \\
(-0.06)\end{array}$ & -0.1 \\
\hline
\end{tabular}

Source: $\quad$ SSA's TRF07 and MEF

Note: DD estimates regression-adjusted to control for differences in 1996 and 1998 cohorts. Within each group, the percentage effect (last column) is the estimate from the previous column divided by the mean earnings in 2000 of the 1998 TWP completers net of the DD estimate for the group.

Finally, the results using AWI-adjusted earnings show a similar significant negative effect of the SGA increase on the percent of the year that beneficiaries were off the rolls for work as the nominal results (Table VIII.3). The AWI-adjusted DD estimate for the total effect is the same as for the estimate using nominal earnings because earnings play no role in the estimate. There are slight differences within earnings intervals, however. For both sets of estimates, we find significant and 
substantial reductions for the earnings intervals below $\$ 1,000$, but they are smaller when AWIadjusted earnings are used.

Table VIII.3 Estimates of the Mean Impact on Months Off the Rolls for Work by AWI-adjusted Earnings Interval in TWP Completion Year, 1996 and 1998 TWP Completer Cohorts

\begin{tabular}{|c|c|c|c|c|c|c|}
\hline & \multicolumn{4}{|c|}{$\begin{array}{c}\text { Increase in Mean Months } \\
\text { Off the Rolls Due to } \\
\text { Work, TWP Year to Two } \\
\text { Years Later }\end{array}$} & \multirow{2}{*}{$\begin{array}{l}\text { DD Estimate } \\
\text { (months) } \\
\text { (t-statistic) }\end{array}$} & \multirow[b]{2}{*}{$\begin{array}{l}\text { Percentage } \\
\text { DD Estimate }\end{array}$} \\
\hline & $\begin{array}{l}1996 \\
\text { Cohort }\end{array}$ & $\begin{array}{l}1998 \\
\text { Cohort }\end{array}$ & $\begin{array}{l}1996 \\
\text { Cohort }\end{array}$ & $\begin{array}{l}1998 \\
\text { Cohort }\end{array}$ & & \\
\hline Total & 100.0 & 100.0 & 2.62 & 2.49 & -0.13 & -3.5 \\
\hline Total Weighted & 100.0 & 100.0 & 2.62 & 2.49 & $\begin{array}{l}(-4.14) \\
-0.13 \\
(-8.42)\end{array}$ & -3.4 \\
\hline $\begin{array}{l}\text { TWP Year Earnings } \\
\text { Less than } \$ 500\end{array}$ & 46.1 & 47.5 & 1.49 & 1.27 & $\begin{array}{l}-0.22 \\
(-6.79)\end{array}$ & -12.8 \\
\hline$\$ 500$ to $\$ 699$ & 14.7 & 13.1 & 2.39 & 1.99 & $\begin{array}{l}-0.41 \\
(-5.53)\end{array}$ & -13.1 \\
\hline$\$ 700$ to $\$ 999$ & 11.7 & 11.2 & 3.15 & 3.20 & $\begin{array}{c}0.05 \\
(0.46)\end{array}$ & 1.0 \\
\hline$\$ 1,000$ or more & 27.6 & 28.2 & 4.41 & 4.50 & $\begin{array}{c}0.09 \\
(1.39)\end{array}$ & 1.3 \\
\hline
\end{tabular}

Source: $\quad$ SSA'S TRF07 and MEF

Note: $\quad$ DD estimates regression-adjusted to control for differences in 1996 and 1998 cohorts. Within each group, the percentage effect (last column) is the estimate from the previous column divided by the mean earnings in 2000 of the 1998 TWP completers net of the DD estimate for the group.

Based on the findings of the earlier comparisons for the 1997 and 1996 cohorts, we believe that the results obtained using nominal earnings more accurately capture the impacts of the SGA increase than the AWI-adjusted estimates presented here. The AWI-adjusted estimates produce some findings that are counter to theoretical predictions such as an increase in the percent with earnings above the new SGA 
This page has been left blank for double-sided copying. 


\section{CONCLUSION AND DISCUSSION}

For a number of reasons described earlier, we limited our analysis to an examination of the impact of the increase in the SGA level on the earnings and months off the rolls for work of the 1998 TWP completer cohort in the second year after TWP completion. Using our preferred estimates (based on nominal earnings), we found statistically significant impacts showing a decrease in the percentage with earnings below the old SGA, a decrease in the percentage with earnings above the new SGA, and an increase in the percentage with earnings between the old and new SGA—all consistent with theoretical predictions.

We did not find statistically significant positive effects on mean beneficiary earnings, but the estimate for all beneficiaries disguises small statistically significant positive effects for those with relatively low earnings in their TWP year, because of opposing effects for those who would have earned more than the new SGA level in the absence of the increase. The largest impacts were for those with TWP-year earnings between $\$ 500$ and $\$ 1,000$ per month, but even in this range the average impact is only about $\$ 18$ per month-less than three percent of the comparison group mean. We found statistically significant negative effects on months off the rolls for work; our preferred estimate is an average reduction of one-quarter of a month, or 6.4 percent of our estimate of the number of months off the rolls for work in the absence of the SGA increase (i.e., the estimated counterfactual). Effects are especially large for those with earnings between $\$ 500$ and $\$ 699$ in the TWP completion year: six-tenths of a month, or over 17 percent of the estimated counterfactual.

Although the impacts of the 1999 SGA increase clearly emerge from the data, and are stronger than those found in earlier studies, they do not appear to be large. Our preferred estimates suggest that between 1.2 and 2.2 percent of beneficiaries in the 1998 TWP completer cohort -773 to 1,418 beneficiaries-parked their earnings in this interval during the second year after TWP completion 
(that is, in 2000). The total number of beneficiaries who parked below the SGA level in 2000 was almost certainly much larger, however, because presumably many beneficiaries from other TWP completer cohorts were also parked.

The impact estimates can be used to make back-of-the envelope inferences about the number of parkers in the average month of any year after 1999, provided that (1) an estimate of the number of beneficiaries who were off the rolls for work in the average month of that year is available, (2) the impact of the 1999 SGA level had the same percentage impact on months off the rolls for work for all beneficiaries in the later years, and (3) the ratio of the upper bound number of parkers to the lower bound for the later year is the same as the ratio among the 1998 TWP cohort in 2000. Stapleton et al. (2010b) find that approximately 200,000 DI beneficiaries were off the rolls because of work in the average month for each year from 2002 through 2006. Based on their estimates and the estimated impacts of the 1999 SGA increase on months off the rolls for work, we arrive at a range of 14,000 to 25,000 parkers in the typical month over this four-year period. ${ }^{11}$ This range is equivalent to 0.2 to 0.3 percent of the average number of beneficiaries on the rolls in December of these years. While this number is small relative to the total number of beneficiaries, it is large relative to the percentage whose benefits are suspended because of work in a typical month (about 0.5 percent) or who are terminated in a typical year (also about 0.5 percent). ${ }^{12}$

Presumably, the number of parkers during the early part of this period was reduced by the weak economy. Hence, in a stronger economy, the number of parkers might be larger than these estimates

11 The lower bound is obtained by assuming that beneficiaries were parked only in the months represented by this impact, and that the same percentage reduction applied to all beneficiaries off the rolls for work after TWP completion in the later year. If $\mathrm{N}$ is the number of beneficiaries off the rolls in the typical month of year $t$, then we estimate the lower bound for the number of parkers is $\mathrm{P}_{\mathrm{L}}=0.064 \mathrm{~N} /(1.0-0.064)=0.068 \mathrm{~N}$ and the upper bound is $\mathrm{PU}^{\mathrm{U}}=2.2 \mathrm{P}_{\mathrm{L}} / 1.2=$ $1.83 \mathrm{P}_{\mathrm{L}}=0.125 \mathrm{~N}$.

12 In December 2006, the benefits of 33,613 DI worker beneficiaries were suspended because of work, representing 0.49 percent of all beneficiaries on the rolls in that month. In all of 2006 (SSA 2007), 36,242 beneficiaries had their benefits terminated because of work, or 0.53 percent of the number of beneficiaries in December. 
suggest. Another reason the number might be larger in later years is that the 1998 cohort might not have had sufficient time to fully adjust to the higher SGA level by 2000. SSA's use of AWI to adjust the SGA level since 2000 might have increased or reduced the number of parkers.

The SGA level has increased with the AWI since 2000. If AWI growth has been more rapid than wage growth in the jobs that beneficiaries typically obtain, it seems likely to have further reduce the number of beneficiaries who have their benefits suspended, and eventually terminated, for work. That does not imply that percentage of beneficiaries who are parked is increasing, however, because some who might have restricted their earnings had the SGA level grown more slowly since 2000 might not do so under the current SGA level.

The findings imply that policy reforms designed to increase work incentives for SSDI beneficiaries capable of SGA could potentially increase the earnings of the small share of beneficiaries who are parked, but might also reduce the earnings of the even smaller share who leave the rolls because of work under current law. SSA's test of the $\$ 1$-for- $\$ 2$ benefit offset for earnings above the SGA level might show increases in earnings for those who are parked under current law, but declines for those who would have left the rolls for work.

We do not know if the SGA increase induced entry into DI. Given the length and uncertain outcome of the DI application process, we would not expect workers to be induced to leave their jobs and apply for benefits because of the increase in the SGA level. Workers who have lost their jobs for other reasons (e.g., during the recession) might, however, find application for DI a more attractive alternative because of the SGA increase, and some might successfully apply. Perhaps more importantly, workers who have lost their jobs for other reasons and would have entered DI even in the absence of the SGA increase are now less likely to leave the rolls for work than they were before the increase. That is, the "reduced exit" of such workers might be a more important phenomenon than their induced entry. 


\section{REFERENCES}

Autor, David H., and Mark G. Duggan. "The Growth In The Social Security Disability Rolls: A Fiscal Crisis Unfolding.” Journal of Economic Perspectives, 20(3):71-96, 2006.

Franklin, Paula A. "Impact of Substantial Gainful Activity Level on Disabled Beneficiary Work Patterns.” Social Security Bulletin, 39(8): 20-29, August 1976.

Franklin, Paula A., and John C. Hennessey. "Effect of Substantial Gainful Activity Level on Disabled Beneficiary Work Patterns." Social Security Bulletin, 42(3):3-17, March 1979.

Imbens, Guido, and Jeff Wooldridge. "Difference-in-Differences Estimation." What's New in Econometrics, Lecture 10. Cambridge, MAL National Bureau of Economic Research, Summer 2007.

Livermore, Gina. "Earnings and Work Expectations of Social Security Disability Beneficiaries." Washington, DC: Mathematica Policy Research, Inc., Center for Studying Disability Policy, Issue Brief 08-01, August 2008.

Social Security Administration. Annual Statistical Supplement to the Social Security Bulletin, 1997 Baltimore, MD: SSA, 1997.

Social Security Administration. Annual Statistical Report on the Social Security Disability Insurance Program, 2000. Baltimore, MD: SSA, September 2001.

Social Security Administration. Annual Statistical Report on the Social Security Disability Insurance Program, 2007. Baltimore, MD: SSA, September 2008

Social Security Administration. The Red Book-A Guide to Work Incentives. Baltimore, MD: SSA, 2010.

Social Security Advisory Board. Disability Programs in the 21st Century: Substantial Gainful Activity. Social Security Advisory Board Issue Brief Series, Vol. 1, No. 3. April 2009.

Stapleton, David, Gina Livermore, Craig Thornton, Bonnie O’Day, Robert Weathers, Krista Harrison, So O’Neil, Emily Sama Martin, David Wittenburg, and Debra Wright. "Ticket to Work at the Crossroads: A Solid Foundation with an Uncertain Future." Washington, DC: Mathematica Policy Research, Inc., September 2008.

Stapleton, David C., Su Liu, Dawn Phelps, and Sarah Prenovitz. "Work Activity and Use of Employment Supports Under the Original Ticket to Work Regulations: Longitudinal Statistics Among New Social Security Disability Insurance Beneficiaries." Washington, DC: Mathematica Policy Research. 2010a.

Stapleton, David C., Jody Schimmel, Miriam Loewenberg, and Sarah Prenovitz. "Work Activity and Use of Employment Supports Under the Original Ticket to Work Regulations: Time that Beneficiaries Spend off the Rolls for Work and the Payments Generated for Employment Networks.” Washington, DC: Mathematica Policy Research. 2010b. 
United States General Accountability Office (GAO). "SGA Levels Appear to Affect the Work Behavior of Relatively Few Beneficiaries, but More Data Needed." Report to the Committee on Finance, U.S. Senate and the Committee on Ways and Means, House of Representatives, January 2002.

Weathers, Robert R. II, and David C. Wittenburg. Employment. Chapter 4 in Andrew Houtenville, David C. Stapleton, Robert R. Weathers II, and Richard V. Burkahuser (eds.) Counting WorkingAge People with Disabilities: What Current Data Tell Us and Options for Improvement. Kalamazoo, MI: W.J. Upjohn Institute for Employment Research, 2009.

United States Census Bureau. 2008 American Community Survey. Table B18120. Accessed using American Fact Finder 8. 


\section{APPENDIX A}

\section{ADDITIONAL TABLES AND FIGURES}


This page has been left blank for double-sided copying. 
Table 1 Descriptive Profile for Disabled Workers receiving SSDI Benefits, 1996 and 2000

\begin{tabular}{|c|c|c|c|c|}
\hline \multirow{3}{*}{ Number of beneficiaries } & \multicolumn{2}{|c|}{1996} & \multicolumn{2}{|c|}{2000} \\
\hline & \multicolumn{2}{|c|}{$4,386,040$} & \multicolumn{2}{|c|}{$5,042,333$} \\
\hline & Number & Percent & Number & Percent \\
\hline $\begin{array}{l}\text { Mean age (years) } \\
\text { Under } 30\end{array}$ & 154,500 & 3.52 & 137,186 & 2.72 \\
\hline $30-39$ & 639,700 & 14.58 & 591,575 & 11.73 \\
\hline $40-49$ & $1,106,700$ & 25.23 & $1,282,978$ & 25.44 \\
\hline $50-59$ & $1,515,300$ & 34.55 & $1,907,348$ & 37.83 \\
\hline $\begin{array}{l}\text { Sex } \\
\text { Men }\end{array}$ & $2,650,020$ & 60.42 & $2,856,410$ & 56.65 \\
\hline Women & $1,736,020$ & 39.58 & $2,185,923$ & 43.35 \\
\hline $\begin{array}{l}\text { Race } \\
\text { White }\end{array}$ & & & $3,707,867$ & 73.53 \\
\hline Black & & & 869,016 & 17.23 \\
\hline Other & & & 426,358 & 8.46 \\
\hline Unknown & & & 39,092 & 0.78 \\
\hline $\begin{array}{l}\text { Primary Impairment } \\
\text { Other Mental Disorders }\end{array}$ & $1,130,600$ & 25.78 & $1,361,157$ & 26.99 \\
\hline Mental Retardation & 228,400 & 5.21 & 257,601 & 5.11 \\
\hline $\begin{array}{l}\text { Diseases of the musculoskeletal system and } \\
\text { connective tissue }\end{array}$ & 946,800 & 21.59 & $1,152,231$ & 22.85 \\
\hline Infectious and Parasitic Diseases & 89,100 & 2.03 & 97,919 & 1.94 \\
\hline Neoplasms & 123,700 & 2.82 & 136,404 & 2.71 \\
\hline Endocrine, nutritional, and metabolic diseases & 199,100 & 4.54 & 244,456 & 4.85 \\
\hline Diseases of the blood and blood-forming organs & 11,000 & 0.25 & 12,070 & 0.24 \\
\hline $\begin{array}{l}\text { Diseases of the nervous system and sense } \\
\text { organs }\end{array}$ & 423,000 & 9.64 & 479,246 & 9.50 \\
\hline Diseases of the circulatory system & 539,300 & 12.30 & 532,998 & 10.57 \\
\hline Diseases of the respiratory system & 160,200 & 3.65 & 166,054 & 3.29 \\
\hline Diseases of the digestive system & 58,900 & 1.34 & 69,735 & 1.38 \\
\hline Diseases of the genitourinary system & 65,800 & 1.50 & 84,687 & 1.68 \\
\hline Congenital anomalies & 16,400 & 0.37 & 8,540 & 0.17 \\
\hline Injuries & 248,400 & 5.66 & 231,066 & 4.58 \\
\hline Other & 83,500 & 1.90 & 113,167 & 2.24 \\
\hline Missing & 69,100 & 1.58 & & \\
\hline
\end{tabular}

Source: $\quad$ SSA (1997) and SSA (2001). 
Figure 1 Cumulative Distribution of Monthly Earnings Among TWP Completers, in the Year After TWP Completion, Earnings Around SGA, 1996-2000 Cohorts

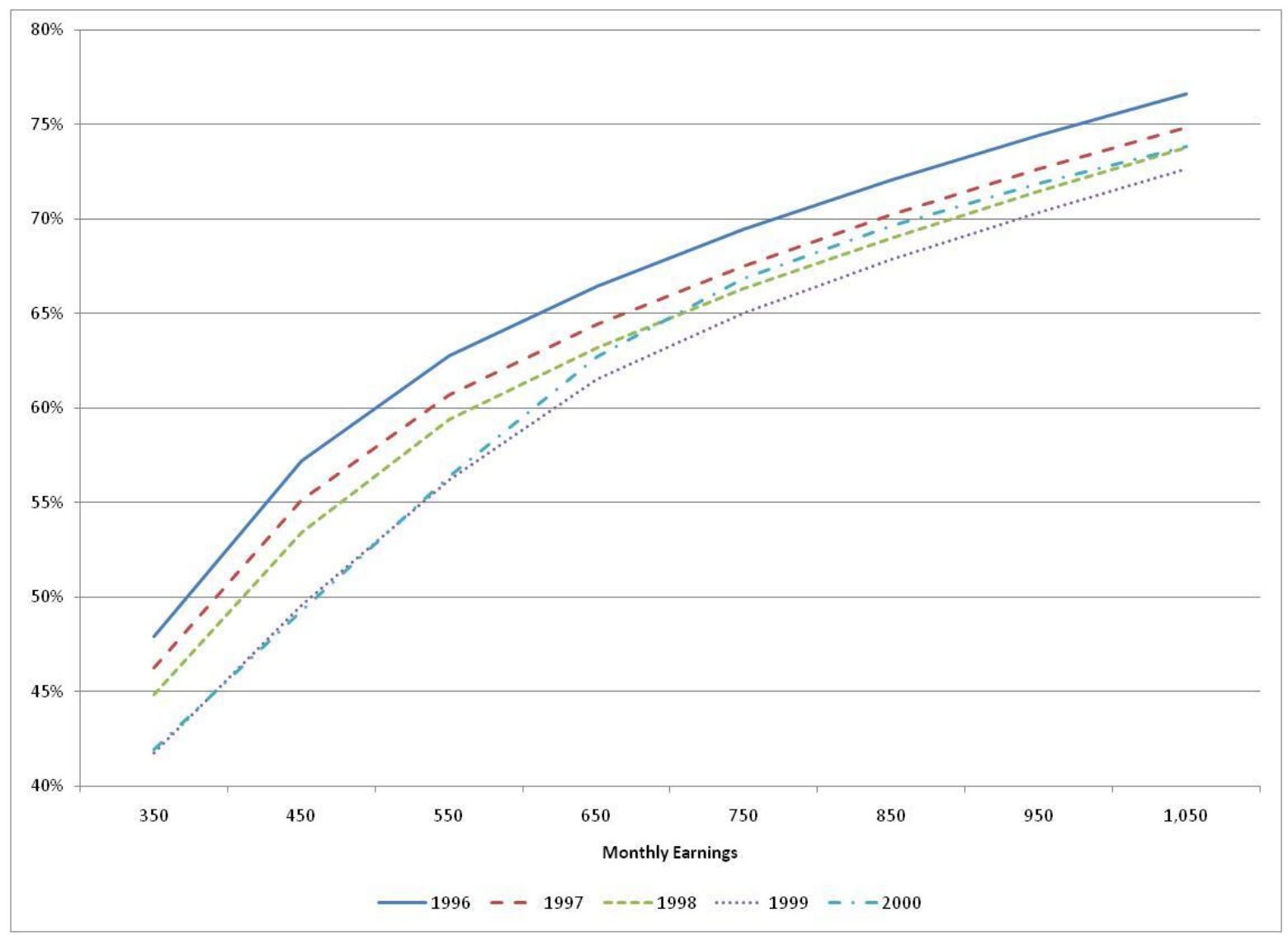

Source: $\quad$ SSA's TRF07 and MEF

Note: Nominal earnings in $\$ 100$ intervals; dollar value denoted is the midpoint of the interval. 
Figure 2 Cumulative Distribution of Monthly Earnings Among TWP Completers, Two Years After TWP Completion, Earnings Around SGA, 1996-2000 Cohorts

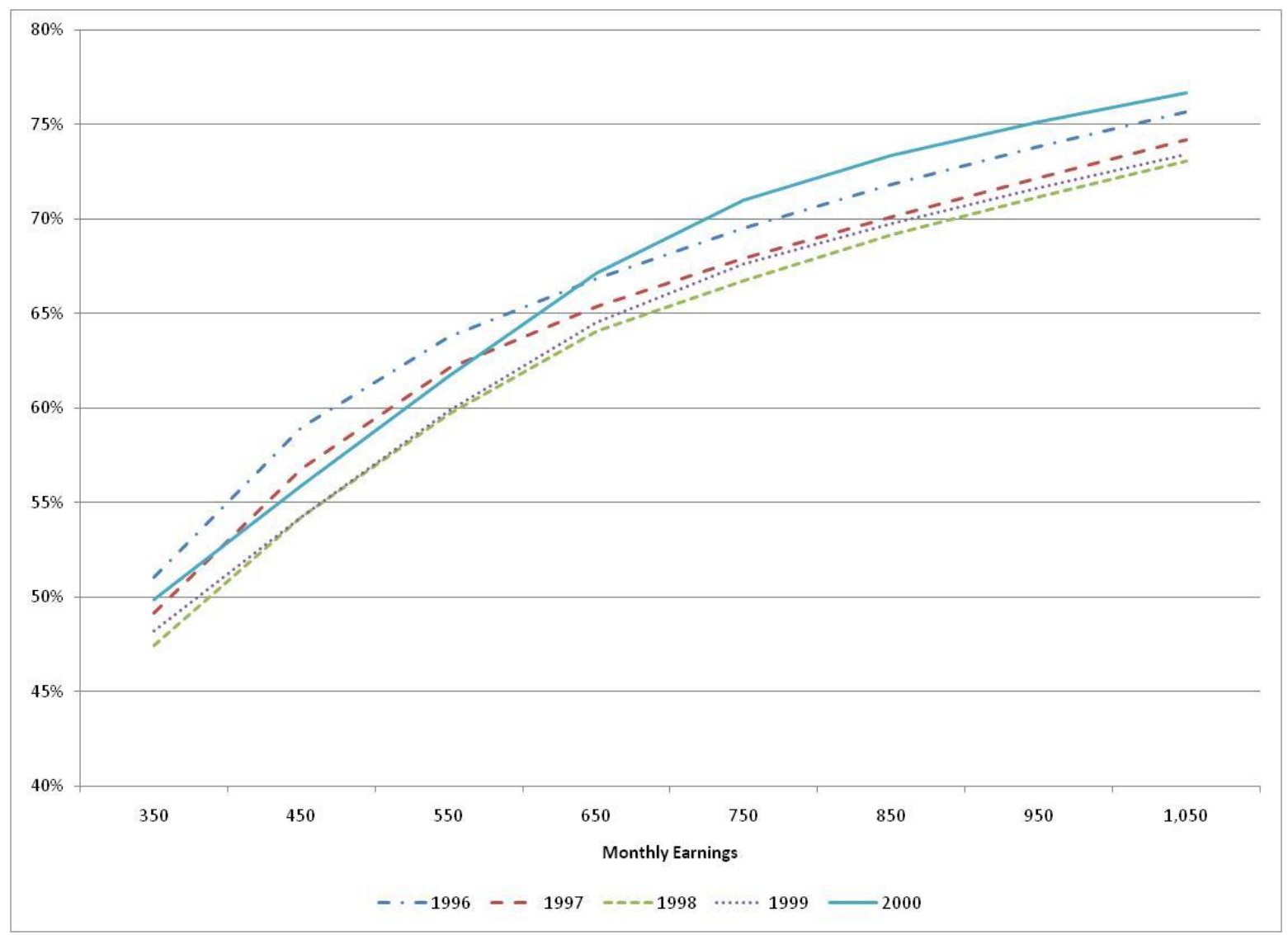

Source: $\quad$ SSA's TRF07 and MEF

Note: Nominal earnings in $\$ 100$ intervals; dollar value denoted is the midpoint of the interval. 
Figure 3 Distribution of Monthly Earnings Among TWP Completers, TWP Completion Years to Two Years Later, 1996 Cohort

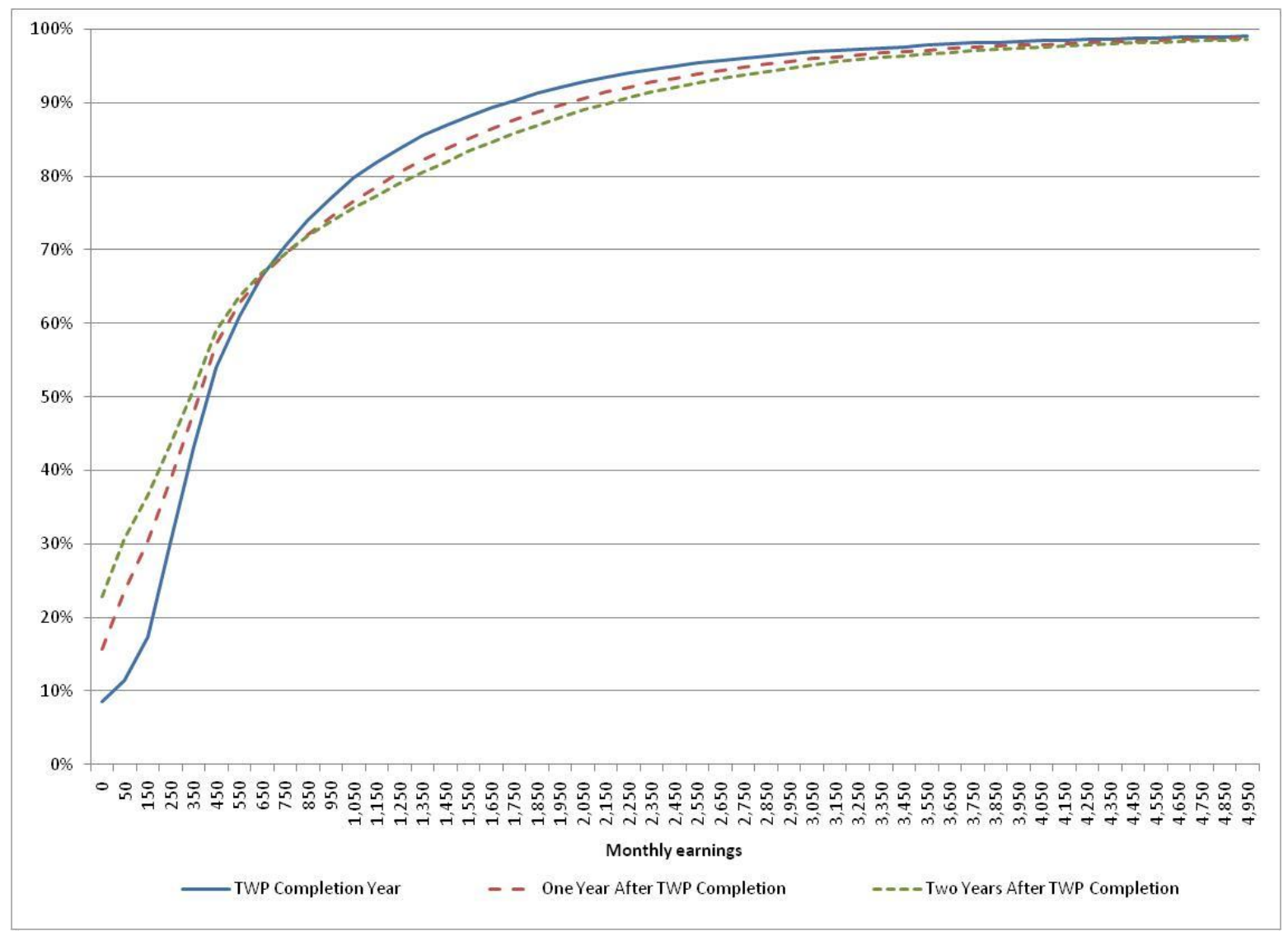

Source: $\quad$ SSA's TRF07 and MEF

Note: Nominal earnings in $\$ 100$ intervals; dollar value denoted is the midpoint of the interval. 
Figure 4 DD Estimates of the Impact of the 1999 SGA Increase on the Cumulative Distribution of Earnings for the 1998 TWP Cohort in the Second Year after TWP Completion

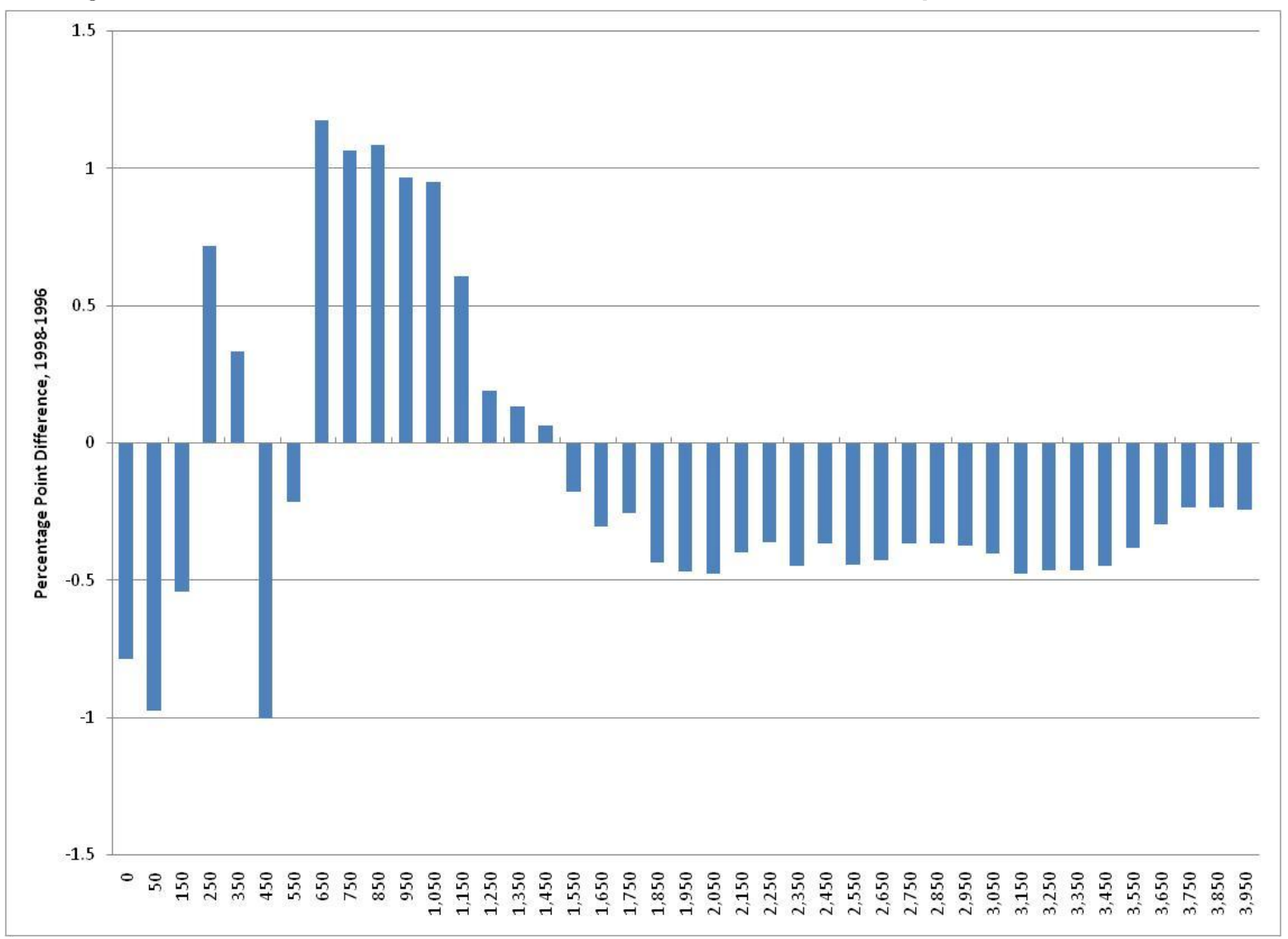

Source: $\quad$ SSA's TRF07 and MEF

Note: Nominal earnings in $\$ 100$ intervals; dollar value denoted is the midpoint of the interval. 